\title{
Las inmunidades diplomáticas en el derecho comparado (México-Estados Unidos) y en el derecho internacional
}

\section{Diplomatic Immunities in Comparative Law (Mexico- United States) and in International Law}

\author{
Juan Manuel Portilla GóMEZ* \\ Imanol DE LA FLOR PATIÑO**
}

\begin{abstract}
SUmario: I. Prolegómenos. II. Aspectos constitucionales compartidos: un ejemplo concreto. III. Visión estadounidense. IV. Visión mexicana. V. Conclusiones. VI. Bibliografía.
\end{abstract}

* Doctor en Derecho Internacional por la UNAM; profesor de tiempo completo, investigador nacional nivel II.

** Maestro en Derecho por la Universidad de Houston; miembro de carrera del Servicio Exterior Mexicano. 
RESUMEN: México y Estados Unidos comparten no sólo una de las fronteras más grandes del mundo sino también instituciones jurídicas a pesar de pertenecer a distintos sistemas legales. Estados Unidos ha construido todo un régimen de inmunidades con estatutos diplomáticos y su ley de inmunidad soberana, combinados con las disposiciones de Viena. Siguiendo el fundamento constitucional estadounidense, México construye la figura de las inmunidades diplomáticas de manera poco clara. Establece desde la primera Constitución la participación del Poder Judicial en las controversias de lo que ahora se conoce como el Servicio Exterior Mexicano para en las sucesivas Constituciones referirse al cuerpo diplomático y consular. Con ello abonó a una mayor ambigüedad en esta materia y ha suscitado una práctica judicial poco consistente con una serie de interpretaciones diversas, a menudo contradictorias. México requiere de una ley de inmunidades que ordene esta materia y que conecte los preceptos constitucionales pertinentes con las normas de Viena.

Palabras clave: inmunidades diplomáticas, estatuto diplomático, ley de inmunidades, cuerpo diplomático.

ABSTRACT: Despite belonging to different legal systems Mexico and the United States share legal institutions along with one of the biggest borders in the world. United States has built an immunity regime combined with Vienna regulations which have crystalized into diplomatic immunity statutes and a Foreign Sovereign Immunities Act. Influenced by the American Constitution, Mexico had understood -however in an obscure fashion-diplomatic immunity. Since its first constitution, Mexico established the involvement of the judiciary in controversies concerning the Mexican Foreign Service, but then in successive Constitutions the reference changed to the diplomatic and consular corps. The latter has only contributed to a greater ambiguity in this matter and has given rise to inconsistent court practice with a number of different interpretations often contradictory. Mexico requires an immunities act to govern and give coherence over this matter and connect the relevant constitutional provisions with the Vienna rules.

Key words: Diplomatic immunity, diplomatic status, Immunities Act, diplomatic corps.

RÉSUMÉ: Le Mexique et les Etats Unis partagent, non seulement une de plus grandes frontières dans le monde, mais aussi des Institutions Juridiques bien qu'elles appartiennent à des différents systèmes légaux. Les Etats Unis ont construit tout un régime d'immunités avec des statuts diplomatique suivant le fondement constitutionnel des Etats Unis, construit la figure des immunités diplomatiques de façon peu claire. Il prévoit dès la première Constitution, la participation du pouvoir judiciaire dans les différends de ce qui est désormais connu aujourd'hui comme le Service Extérieur Mexicain pour se référer, dans les constitutions successives, au corps diplomatique et consulaire. Cela a engraissé à une plus grande ambiguïté dans ce domaine et a suscité une pratique judiciaire peu consistant avec une série d'interprétations différentes, souvent contradictoires. Le Mexique exige une Loi d'Immunités qui règle cette matière et qui relie les préceptes constitutionnels pertinents avec les principes de Vienne.

Mots-clés: Immunités diplomatiques, statut diplomatique, loi d'immunités, corps diplomatique. 
Esta revista forma parte del acervo de la Biblioteca Jurídica Virtual del Instituto de Investigaciones Jurídicas de la UNAM

\section{Prolegómenos}

Podría pensarse que las fronteras sólo marcan cotas para la otredad; que son divisiones más allá del mero ámbito geográfico, útiles para acentuar lo que no se es en términos culturales. Los sistemas jurídicos no escaparían a esta dinámica de no ser por un estado de mayor agudeza intelectual que actualmente postula un cambio de paradigma: ${ }^{1}$ en realidad las fronteras son meros tránsitos, porosos canales de comunicación, contingentes y flexibles hasta el punto de reconstituirse en ciclos históricos.

En este sentido, la frontera entre México y Estados Unidos² resulta un ejemplo sumamente útil para demostrar esa premisa. En esta investigación nos centraremos en aspectos constitucionales que si bien resultan por mucho compartidos, en algún punto han seguido caminos diferentes. De ahí la importancia de un ejercicio comparativo a la luz del desarrollo jurídico que una y otra nación ha desarrollado a lo largo de su historia.

1 Abu Warda, Nahib, "Las migraciones internacionales", Revista de Ciencias de las Religiones, Universidad Complutense de Madrid, Anexo XXI, 2007, pp. 41-43; Skoczek, María "Globalización y Migraciones a caballo de los siglos XX y XXI", Actas Latinoamericanas de Varsovia, t. 27 integración versus globalización, efectos sociales, económicos y especiales, Universidad de Warsawa, Instituto de Países en Desarrollo, 2004, http://www.wgsr.uw.edu.pl/pub/uploads/ actas04/04-skoczek.pdf, pp. 83 y 84; Velasco, Juan Carlos, "Dejando atrás las fronteras. Las Políticas migratorias ante las exigencias de la Justicia Global”, ARBOR Ciencia, Pensamiento y Cultura, Consejo Superior de Investigaciones Científicas, España, julio-agosto 2010, p. 595; Zapata-Barrero, Ricard, "La retórica de la ciudadanía y la inmigración”, Revista Claves de la Razón Práctica, Universidad de Barcelona, núm. 177, noviembre de 2007, pp. 329 y 330; Ferrajoli, Luigi, "Libertad e inmigración”, Revista Internacional de Filosofía Política, Universidad Nacional de Educación a Distancia, España, núm. 22, 2003, en http: / dialnet.unirioja.es / servlet/articu lo?codigo=930442, (consultada el 3 de junio de 2015); Carbonell, Miguel, "Las fronteras y los derechos fundamentales", Obra en homenaje a Rodolfo Cruz Miramontes, México, UNAM, 2008, t. II, in totum.

2 La Frontera entre Estados Unidos y México representa un sistema geopolítico binacional basado en fuertes vínculos sociales, económicos y culturales. A manera de ejemplo destacamos que con sus 3185 kilómetros de longitud, es el cruce internacional más poblado y activo del mundo. Desde la promulgación del Tratado de Libre Comercio de América del Norte (TLCAN), y dada la complementariedad de las economías de Estados Unidos y México, el comercio transfronterizo ha crecido exponencialmente, alcanzando una cantidad récord de alrededor de $\$ 400,000$ millones de dólares en 2010, por ejemplo. Véase North American Center for Transbounder Studies, Reconociendo el valor real del comercio bilateral con Mexico, Estados Unidos, Arizona State University, 2010, p. 2 
Esta revista forma parte del acervo de la Biblioteca Jurídica Virtual del Instituto de Investigaciones Jurídicas de la UNAM

México — país de tradición jurídica romanista — surge a la vida independiente en 1821 con el ánimo de una generación que pugnaba por quebrar los modelos heredados del tiempo colonial. Independientemente de la borrascosa y breve monarquía constitucional, finalmente adopta un régimen republicano y, en ese sentido, busca una lejanía de los modelos hispanos. México desea constituirse desde los cimientos y, para ello, se provee una primera Constitución como nación independiente en $1824 .{ }^{3}$ Esta traería consigo una nueva mecánica y un discurso diferente al español. México no desea ver en ese momento allende el Atlántico. ${ }^{4}$

Por su parte, Estados Unidos, colonia americana de un imperio, igual que México, tiene un cariz distinto para su metrópoli en comparación del que prevalecía para la Nueva España en la península ibérica. Estados Unidos pues, nace en 1787 bajo un esquema distinto al mexicano. No sólo la religión ni el idioma sino la relación con el derecho anglosajón modelan las necesidades y los límites y alcances del nuevo país. ${ }^{5}$ Estados Unidos decide, a diferencia de México, continuar con el bagaje jurídico venido de su metrópoli por cuanto hacía al case law. ${ }^{6}$

3 La historia constitucional mexicana nace con una influencia concreta, brindada tanto por el Estatuto de Bayona de 1808 como por la Constitución de Cádiz de 1812. La médula ideológica liberal de ambos documentos sentó las bases para la de Apatzingán de 1814 con un preclaro acento ilustrado. Todos estos antecedentes confluyen en la Constitución de 1824, que sin embargo como reconoce Migallón tiene una fuerte influencia estadounidense aunque sin desprenderse del núcleo francés de un catálogo de derechos mucho más amplio y de una interpretación constitucional centrada en el texto como código descriptivo y no sólo enunciativo o emulativo. Véase Tena Ramírez, Felipe, “Constituciones”, Leyes fundamentales de México, 1808-1982, 1982; Rabasa, Emilio O., Historia de las Constituciones mexicanas, México, UNAM, 2000; Serrano, Fernando, Historia mínima de las Constituciones en México, 2013; Eissa-Barroso, Francisco A., "Mirando hacia Filadelfia desde Anáhuac: la Constitución estadounidense en el Congreso Constituyente mexicano de 1823-1824”, Política y Gobierno 17.1, 2010, pp. 97-125.

4 Arenal Fenochio, Jaime del, Un modo de ser libres: independencia y constitución en México (1816-1822), El Colegio de Michoacán, 2002, pp. 221-235; Bravo Lira, Bernardino, ”El derecho indiano después de la independencia de América Española. Legislación y doctrina jurídica”, Historia, Santiago, núm. 19, 1984, pp. 5-51. Ambos autores coinciden en reafirmar que si bien la Constitución como hito fundacional del Estado se vio imbuida por un discurso renovador. En la praxis el derecho indiano siguió vivo no solo por comodidad sino también por la formación académica de los operadores de derecho.

5 Corwin, Edward S., "The Higher Law Background of American Constitutional Law", Harvard Law Review, 1929, pp. 370-371, 385-387.

6 La Enciclopedia de Derecho Estadounidense lo define del siguiente modo: "Legal principles enunciated and embodied in judicial decisions that are derived from the application of particular areas of law to the facts of individual cases. As opposed to statutes, legislative acts that 
Esta revista forma parte del acervo de la Biblioteca Jurídica Virtual del Instituto de Investigaciones Jurídicas de la UNAM

Ello no es para sorprender sino más bien representa una prudente muestra de continuidad por razones prácticas. Así, para no detener de golpe la construcción de derecho por las cortes estadounidenses, resultaba más prudente respetar los precedentes venidos de Inglaterra y, paulatinamente, construir los nuevos paradigmas americanos. ${ }^{7}$ Para ello, Estados Unidos se provee de una nueva Constitución. En ella el discurso es renovador y de cierta forma cumple una doble función: ${ }^{8}$ mantiene unidos los lazos verdaderamente necesarios con el derecho anglosajón, en tanto marca una diferencia discursiva y de acción nueva, diferente al modelo inglés, para el país recién nacido.

Mientras que México rompe con la dialéctica de la metrópoli, Estados Unidos la conserva como un puente. ¿En dónde se encuentra la comunión entre ambos países? Sumado a lo anterior, cabe enunciar la obvia diferencia temporal entre ambos momentos históricos.

Las cartas magnas de México y Estados Unidos nacieron en dos siglos distintos; la nuestra en 1824 y la suya en 1787. Casi cuatro décadas entre una y otra quizás aportaron un aura de confianza para México; finalmente eran una muestra de funcionamiento para un país formado después de once años de lucha independentista. Como mencionamos antes, México quiso romper el discurso jurídico compartido con España y así encuentra, quizás una breve coincidencia, probablemente bajo cierto ánimo aspiracional, para proveerse de un discurso propio a partir de la impronta estadounidense. He ahí la comunión. ${ }^{9}$

proscribe certain conduct by demanding or prohibiting something or that declare the legality of particular act as law is a dynamic and constantly developing body of law. Each case contains a portion wherein the facts of the controversy are set forth as well as the holding and dicta an explanation of how the judge arrived at a particular conclusion. The concept of precedent, or stare decisis, means to follow or adhere to previously decided cases in judging the case at bar. It means the appellate case law should be considered as binding upon lower courts, Encyclopedia of American Law".

7 Corwin, Edward, op. cit., pp. 378-380.

8 Strauss, David A., "Common law constitutional interpretation", The University of Chicago Law Review , 1996, pp. 883 y 884. El autor refiere que el rol de la Constitución en el Sistema Jurídico Americano es de una vitalidad relativa. Es decir el valor del texto llega a ser nominal — si bien jerárquicamente superior - en la medida en que es el common law y el desarrollo jurídico de las Cortes [modelo heredado de Inglaterra] los que van a permitir el desarrollo e interpretación del propio texto.

9 Smith, Watson, "Influences from the United States on the Mexican Constitution of 1824”, Arizona and theWest, 4.2,1962, pp. 113-126, y Knowlton, Robert J., The Early Influence 
Esta revista forma parte del acervo de la Biblioteca Jurídica Virtual del Instituto de Investigaciones Jurídicas de la UNAM www.juridicas.unam. $\mathrm{mx}$

Ciertamente, la estructura de la Constitución estadounidense es más que punta de lanza, consecuencia lógica de una dinámica histórica tendiente a valores democráticos para constituir un aparato de gobierno mucho más eficiente que el de las metrópolis. ${ }^{10}$ El modelo resulta tentador, México entonces retoma con una técnica constitucional propia principios contenidos en el marco constitucional americano ${ }^{11}$ y a lo largo de nuestra historia los replica con matices parroquiales en los textos subsecuentes de 1857 y 1917, este último vigente.

Esta incardinación responde a un flujo. La cercanía entre ambos países, provoca que sus fenómenos domésticos, sus problemas y las soluciones a estos, impacten en el vecino. Creemos que la influencia de la Constitución estadounidense en la mexicana es una muestra de cómo las fronteras tienen el espíritu de puertas para el tránsito. Como inferimos en un principio, la otredad no debe separar sino más bien marcar los puntos de contacto existentes. Resultan innegables nuestras diferencias con Estados Unidos en múltiples planos, no obstante, es imposible negar nuestras mutuas influencias.

\section{ASPECTOS CONSTITUCIONALES COMPARTIDOS: UN EJEMPLO CONCRETO}

Las líneas anteriores son un medio para abstraer una de las premisas de nuestro discurso: la Constitución mexicana tiene figuras estadounidenses en su estructura; algunas tan poco estudiadas que pudieran acarrear futuras lagunas de interpretación. Tal es el caso de la incorporación del derecho internacional a sus sistemas domésticos en general y del régimen de inmunidades diplomáticas en particular. ${ }^{12}$

of the United States Constitution in the Western Hemisphere: The Cases of the Mexican Constitution of 1824 and Bolivar's Ideas, University of Wisconsin-Milwaukee, Center for Latin America, 1988.

10 Dahl, Robert Alan, How Democratic is the American Constitution?, Yale University Press, 2003, pp. 141-145

11 Knowlton, op. cit., pp. 30-32.

12 Para un análisis sobre la incorporación del derecho internacional y del derecho diplomático en México, véase Becerra Ramírez, Manuel, La recepción del derecho internacional en el derecho interno, México, UNAM, Instituto de Investigaciones Jurídicas, 2012, y Portilla Gómez, Juan Manuel, "El Estado mexicano como sujeto del derecho diplomático", Revista Mexicana de Política Exterior, núm. 79-80, 2007. 
Esta revista forma parte del acervo de la Biblioteca Jurídica Virtual del Instituto de Investigaciones Jurídicas de la UNAM www.juridicas.unam.mx

En torno al primer tema, considerado como un preámbulo para el segundo, destaca la incorporación de una cláusula de supremacía que otorga al derecho internacional — de fuente convencional y costumbre-carácter de norma doméstica y de alta jerarquía. ${ }^{13}$ Sin embargo, el punto anterior se bifurca conforme ha evolucionado la historia constitucional de ambos países.

En México, por ejemplo, la Suprema Corte de Justicia de la Nación ha sido más comprensiva sobre el papel jugado por el derecho internacional en sede doméstica. Desde 1992 se da paso a una nueva estructura jerárquica que sitúa a los tratados sólo por debajo de la Constitución. ${ }^{14}$ Esto último, sigue evolucionando ${ }^{15}$ hasta tomar un nuevo matiz cuando en 2011 se reforma el artículo 1o. constitucional y entonces decide en la contradicción de tesis 293/2011 que los tratados de derechos humanos comparten la cúspide del sistema con la Constitución. ${ }^{16}$ Esto último a partir de un nove-

13 Dickinson, Edwin D., "The Law of Nations as Part of the National Law of the United States”, University of Pennsylvania Law Review, 1952, pp. 30-36; Becerra Ramírez, Manuel et al., "Tratados internacionales se ubican jerárquicamente por encima de las leyes y en un segundo plano respecto de la Constitución Federal (Amparo en revisión 1475/98)", Cuestiones Constitucionales. Revista Mexicana de Derecho Constitucional, México, núm. 3, julio-diciembre de 2000, pp. 172-176.

14 Tratados internacionales. El artículo 133 CONSTituCional, ÚlTima Parte, NO ESTABLECE SU OBSERVANCIA PREFERENTE SOBRE LAS LEYES DEL CONGRESO DE LA UNIÓN EMANADAs DE La CONSTitución Federal, Gaceta del Semanario Judicial de la Federación, t. 60, diciembre de 1992, Tesis P. C/92, p. 27; TRATADOS INTERNACIONALES Y LEYES DEL CONGRESO DE LA Unión EMANADAS DE LA CONSTitución FEDERAL. Su RANGO CONSTitucional ES DE IGUAL JERARQuía, Semanario Judicial de la Federación, Séptima Época. Tercer Tribunal Colegiado en Materia Administrativa del Primer Circuito, t. 151-156, Sexta Parte, p. 196.

15 En 1999 la Suprema Corte de Justicia de la Nación elaboró una tesis en la que se aparta del criterio que había venido sosteniendo, al resolver en un caso concreto: el amparo en revisión 1475/98, promovido por el Sindicato Nacional de Controladores de Tránsito Aéreo. En dicho asunto se resolvió que debería privar la aplicación del convenio 87 de la OIT, que se refiere a libertad sindical, sobre las disposiciones contenidas en la Ley Federal de los Trabajadores al Servicio del Estado; y se determinó que los tratados internacionales se ubican jerárquicamente por encima de las leyes federales y en un segundo plano respecto de la Constitución Federal. Se trata de la tesis de Pleno LXXVI/99, TrATADOS INTERNACIONALES SE UBICAN JERÁRQUICAMENTE POR ENCIMA DE LAS LEYES FEDERALES Y EN UN SEGUNDO PLANO RESPECTO DE LA CONSTITUCIÓN FEDERAL, aprobada en la sesión privada del 28 de octubre de 1999.

16 Véase Contradicción de Tesis 293/2011, "SCJN determina que las normas sobre derechos humanos contenidas en Tratados Internacionales tienen rango constitucional", http: // 
Esta revista forma parte del acervo de la Biblioteca Jurídica Virtual del Instituto de Investigaciones Jurídicas de la UNAM

doso y, ciertamente, aun indefinido criterio de la Corte Interamericana de Derechos Humanos. ${ }^{17}$

Con independencia de esa excepcional posición jerárquica, ${ }^{18}$ lo relevante para esta primera parte de nuestro trabajo es destacar que las propias características de la interpretación constitucional en México, sumadas a su comprensión del federalismo, han permitido una incorporación directa de tratados y, especialmente, la inexistencia de reglas que obstaculicen su aplicación como fuente normativa directa en sede doméstica luego de ser ratificados. ${ }^{19} \mathrm{Tal}$ ha sido el caso de las Convenciones de Viena sobre Relaciones

www2.scjn.gob.mx/ asuntosrelevantes/pagina/seguimientoasuntosrelevantespub.aspx?id=129659\&seg uimientoid=556 (consultada el 25 de julio de 2015).

Sumado a lo anterior véase Silva García, Fernando, "Derechos humanos y restricciones constitucionales: Reforma constitucional del futuro vs. Interpretación constitucional del pasado (Comentario a la C.T. 293/2011 del Pleno de la SCJN)", Cuestiones Constitucionales. Revista Mexicana de Derecho Constitucional, núm. 30, enero-junio de 2014, p. 257. El autor refiere que la Corte concluye, básicamente: 1) Los derechos humanos reconocidos en la Constitución y en los tratados internacionales adoptados por el Estado mexicano conforman el parámetro de validez de toda actualización pública, y 2) Los posibles conflictos y antinomias entre derechos humanos y la Constitución y los tratados internacionales se resolverán conforme al principio pro homine y no en términos jerárquicos.

17 Carbonell refiere: el control de convencionalidad es uno de los puntos culminantes del conjunto de cambios que trajo consigo la reforma de 2011. La explicación de su punto es quizá, de cierto modo, la nacionalidad mexicana de la figura conformada en varios votos separados de Sergio García Ramírez. Ciertamente no es sino hasta 2006 que con el caso Almonacid Arellano v. Chile la figura fragua en el párrafo 124 del fallo.

18 Para un panorama general de la esquematización que gozan, en diversos países de Latinoamérica, los criterios jerárquicos concernientes a Tratados véase: Ayala Corao, Carlos, "La Jerarquía constitucional de los tratados relativos a derechos humanos y sus consecuencias", en Méndez Silva, Ricardo (coord.), Derecho Internacional de los derechos humanos. Memoria delVII Congreso Iberoamericano de Derechos Constitucional, México, UNAM, Instituto de Investigaciones Jurídicas, 2002, p. 40.

Cabe señalar que desde nuestra perspectiva, esta variación a la regla general solo se admite en materia de derechos humanos. Así, la incorporación se da por sentada gracias a la interpretación sistemática de la cláusula del 133 y del artículo 1o.; de tal suerte que la nómina de derechos humanos en el catálogo mexicano es meramente enunciativo no limitativo pues aquellos derechos de fuente convencional pueden ser litigados en sede domestica gracias al Juicio de Amparo.

19 Para un texto de referencia clásico se recomienda Starke, Joseph Gabriel. "Monism and Dualism in the Theory of International Law”, BritishYear Book of International Law, 17, 1936, p. 66. Asimismo, un enfoque más reciente es brindado por: Koh, Harold Hongju. "Why do Nations Obey International Law?”, 1997, pp. 2648-2653. Desde la perspectiva latinoamericana 
Esta revista forma parte del acervo de la Biblioteca Jurídica Virtual del Instituto de Investigaciones Jurídicas de la UNAM

Diplomáticas y Consulares de $1961^{20}$ y $1963 ;^{21}$ así como las Convenciones sobre Privilegios e Inmunidades de las Naciones Unidas y de los Organismos Especializados de 1946 y 1947. Nos centraremos en la primera (Viena, 1961) para articular nuestro discurso.

Esto último se ha traducido en un sistema de tratados comprensivo que opera per se sin necesidad de criterios de interpretación que aclaren a profundidad detalles relativos a su interacción con normas procesales, municipales, estatales o federales. De tal suerte, el régimen de inmunidades provisto por Viena toma carta de naturalización en el sistema y con contadas excepciones, como más adelante se verá, ha sido analizada por los tribunales mexicanos.

En Estados Unidos la situación es distinta. Si bien la cláusula de supremacía opera en un sentido similar al mexicano, lo que ha variado es el criterio de interpretación que los tribunales federales de aquel país han dado a la aplicación del derecho internacional en su sistema. No obstante ser considerado law of the land ${ }^{22}$ encuentra un obstáculo en su aplicación si las cortes consideran que el tratado per se no opera en sede doméstica y

se recomienda la lectura de Acevedo, Domingo, "Relación entre el Derecho internacional y el Derecho interno”, Revista del Instituto Interamericano de Derechos Humanos, núm. 2, vol. 16, julio-dicembre de 1992, pp. 136-138.

20 La Convención entró en vigor el 24 de abril de 1964. Estados Unidos es Estado Parte delTratado desde el 13 de noviembre de 1972; México desde el 16 de junio de 1965. Para destacar la relevancia de la Convención de Viena, referimos lo expresado por Wickremasinghe: "With 180 parties, the VCDR is amongst the most widely ratified of all international conventions, and it is probable that even those of its aspects which were originally progressive development of the law are now considered to reflect customary international law". Wickremasinghe, Chanaka, en Evans, Michael, International Law, Oxford University Press, 2003, p. 392.

21 La Convención entró en vigor el 19 de marzo de 1967. Estados Unidos es Estado Parte del Tratado desde el 13 de noviembre de 1972; México desde el 16 de junio de 1965.

22 The Paquete Habana, 175 U.S. 677, 678, 20 S.Ct. 290, 291 (1900). La doctrina coincide en comentar que este caso es el primero en hacer un statement de gran fuerza sobre la vigencia del derecho internacional como parte del sistema jurídico americano. El fraseo: "international law is part of our law" resulta de suma contundencia. Sin embargo, a partir de otros land marks en materia internacional la Corte Suprema de los Estados Unidos se aparta de esa teoría mucho más conciliadora — similar a la monista - y adopta el enfoque dualista que, finalmente, fragua en la sentencia de Medellin v. Texas según la cual el derecho internacional no necesariamente tiene un caracter vinculante ni su aplicación es considerada por salud constitucional.

Ramsey, Michael D., The constitution's text in foreign affairs, Harvard University Press, 2007, pp. 362-364 
Esta revista forma parte del acervo de la Biblioteca Jurídica Virtual del Instituto de Investigaciones Jurídicas de la UNAM www.juridicas.unam. $\mathrm{mx}$

requiere un acto legislativo interno posterior a la ratificación (non-self executive treaty). ${ }^{23}$ Esto último - innovación anglosajona- ${ }^{24}$ se traduce en un análisis casuístico que las Cortes hacen para determinar si el tratado provee un derecho de acción per se a quien solicite la labor de la Corte y, de proveerlo, se revisa entonces si es viable su aplicación sin una norma doméstica que abunde en mayores detalles. ${ }^{25}$

Sumado a lo anterior, aun si el tratado es considerado self executive en caso de una colisión con leyes federales, estas últimas podrían gozar un rango de preeminencia sobre aquél. ${ }^{26}$ La Convención de Viena se considera self executive sin embargo para permitir una aplicación mucho más detallada del régimen de inmunidades provisto por el tratado se creó en 1978 la Diplomatic Relations Act. ${ }^{27}$

23 Por considerarlo de relevancia, citamos textualmente este breve extracto de Carlos Manuel Vázquez: "At a general level, a self-executing treaty may be defined as a treaty that may be enforced in the courts without prior legislation by Congress, and a non-self executing-treaty, conversely, as a treaty that may not be enforced in the courts without prior legislative "implementation". This definition helps us understand the domestic allocation-of-powers function of the distinction: it allocates between the judiciary and the legislature the responsibility for enforcing compliance with treaties by everyone else (private individuals, state and federal executive officials, state legislatures). But the doctrine allocates this responsibility only provisionally”. Vázquez, Carlos Manuel, "The Four Doctrines of Self Executing Treaties”, 89 A.J.I.L. 695-696.

24 En un ya clásico artículo, Jordan Paust, inicia su discurso al afirmar con soltura: "The distinction found in certain cases between self-executing and non-self-executing treaties is a judicially invented notion that is patently inconsistent with express language in the Constitution affirming that all Treaties... shall be the supreme law of the Land". Paust, Jordan J., "Self-Executing Treaties", The American Journal of International Law, vol. 82, núm. 4, octubre de 1988 , p. 760.

25 Destaca en este sentido, el holding provisto en el reciente caso Igartúa v. United States, 626 F.3d 592, 611 resuelto por la 1a. Corte de Circuito de los Estados Unidos, en 2010, según el cual: "Even if we were to find that the treaty is self-executing, however, difficult questions would remain. Among them are whether the treaty's provisions in fact oblige the United States to provide all of its citizens the right to elect voting members of the House of Representatives and whether the treaty provides for a private right of action as a vehicle for pursuing that right".

26 Yuji Iwasawa, "The Doctrine of Self-Executing Treaties in the United States: A Critical Analysis”, 26 Va.J. Int'1 L., 1986, pp. 654-70. En este sentido, las cortes han desarrollado una serie de excepciones a la auto ejecutividad del Tratado cuando se observe un "animo claro" (aun cuando sea obscuro el medio que la Corte use para determinar dicha claridad) de los Estados-parte en hacer que el Tratado gozara de esta calidad.

27 Para un panorama general sobre la norma desde la perspectiva convencional véase Buergenthal, Thomas et al., Public International Law in a Nutshell, West Publishing Company, 2002, 
Esta revista forma parte del acervo de la Biblioteca Jurídica Virtual del Instituto de Investigaciones Jurídicas de la UNAM

A manera de corolario baste decir que el sistema de incorporación en ambos países es diferente. Aun cuando el espíritu de la cláusula de supremacía es el mismo pues permite al derecho internacional tener un nicho especial en la articulación del sistema doméstico; por otro lado, la labor de cada Poder Judicial ha impactado sustancialmente en la concreción de diferencias interpretativas. Esto último se debe a que el rol de las cortes no es el mismo — ni en su alcance ni en sus herramientas interpretativas - en países del common law que de civil law. ${ }^{28}$

En México, la Convención de Viena no necesitó una norma jurídica para aplicarse de forma directa y, en este sentido, su aplicación ha sido consecuencia del acto de ratificación mismo; con lo que podría inferirse un acuerdo total con el texto de la Convención y con el régimen de inmunidades que esta provee sin mediar "mexicanismo" alguno en la comprensión de sus figuras. Esto último, si bien representaría un signo de respeto al tratado, permitiendo que su evolución proviniera de la práctica recogida por organismos o cortes internacionales sin limitarla con tintes nacionales; por otro lado, podría traducirse en la falta de herramientas interpretativas suficientes para los tribunales mexicanos y, en ese sentido, su aplicación

pp. 210 y 211. Para comprender la visión estadounidense del derecho internacional en su veta convencional a través de dicha norma: O’Neill, Terry A., “A New Regime of Diplomatic Immunity: The Diplomatic Relations Act of 1978”, Tulane Law Review, 54, 1980, pp. 661-663.

$28 \mathrm{Al}$ respecto se recomienda el interesante texto de Merryman en coautoría con PerezPerdomo: Merryman, John Henry y Pérez-Perdomo, Rogelio, The Civil Law Tradition: an Introduction to the Legal Systems of Europe and Latin America, Stanford University Press, 2007. Sin embargo, amén de la recomendación, para textos con menor grado de generalización, recomendamos leer a Tiersma y al mismo Merryman quienes exponen con sumo detalle el rol tan diverso que juegan las Cortes en países de Civil Law en comparación con el que poseen en países anglo-sajones principalmente. Para ello se basan en una detallada descripción de las diferencias formativas en los abogados (el hecho de que en países romanistas el derecho internacional suele ser materia obligatoria en las matriculas en tanto que en los anglo-sajones es electiva), en el método de razonamiento que utilizan (en los primeros el silogismo clásico, en el segundo el método IRAC), en la vinculación existente entre los poderes legislativo y judicial (en los primeros países la codificación y su interpretación en casos concretos es símbolo de interacción entre ambos, cuestión que en pases anglosajones no sucede con el mismo talante, las Cortes son las que deciden el derecho como afirmara Marshall en Marbury v Madison); sumado a las diferentes fuentes del derecho (falta de precedente en common law, la codificación latente en países romanistas). Todo ello imbuye la interpretación del derecho internacional y su incorporación. Merryman, John Henry, "On the Convergence (and Divergence) of the Civil Law and the Common Law”, Stan. J. Int'l L. 17, 1981, pp. 357 y 358; Tiersma, Peter, “The Textualization of Precedent”, Notre Dame Law Review, 82, 2007, p. 118. 
Esta revista forma parte del acervo de la Biblioteca Jurídica Virtual del Instituto de Investigaciones Jurídicas de la UNAM www.juridicas.unam. $\mathrm{mx}$

hasta la fecha ha sido un tanto mínima y no sin cierto talante de oscuridad como se verá más adelante.

En Estados Unidos, la aplicación de una ley federal más detallada que la Convención, probablemente haya brindado mayor claridad sobre los alcances de su aplicación en las cortes americanas; aun cuando esto no ha evitado diferencias entre los criterios de interpretación surgidos en diversas cortes federales proclives a observar los requisitos impuestos por la Diplomatic Relations Act más que el texto del propio tratado. Con ello, la práctica judicial en aquel país ha construido un esquema de reglas para aplicar inmunidades que sin romper necesariamente con el espíritu de Viena resultan — con un eufemismo de por medio — una "innovación" estadounidense. ${ }^{29}$

A partir de la mecánica de incorporación que cada país se ha dado surgen diferencias en la articulación del tratado como norma interna, particularmente en torno al régimen de inmunidades. Abordemos, pues, el segundo tema con la idea anterior en mente.

El régimen de inmunidades contenido en la Convención de Viena ${ }^{30}$ es resultado de una cuidadosa compilación y depuración de normas consuetudinarias rectoras del quehacer diplomático por siglos. ${ }^{31}$ Con su entrada en vigor se buscó la aplicación de un parámetro de minimis para la comunidad internacional, sobre el cual la práctica tanto de tribunales domésticos como de Ministerios de Asuntos Exteriores pudiera cimentarse. ${ }^{32}$ Sí, con

29 O’Neill, Terry, op. cit. pp. 662. Asimismo, Brower, Charles H., "International Immunities: Some Dissident Views on the Role of Municipal Courts”, Va. J. Int'l L. 41, 2000, pp. 22 24, y Farhangi, Leslie Shirin, "Insuring Against Abuse of Diplomatic Immunity", Stanford Law Review, 1986, pp. 1517-1547.

30 Para un seguimiento de las inmunidades contenidas en la Convención de Viena bajo un enfoque del Common Law, véase Denza, Eileen, Diplomatic Law, Commentary on The Vienna Convention on Diplomatic Relations, Oxford University Press, 2008. Para un estudio de las inmunidades diplomáticas bajo un enfoque de civil law, véase Salmon, Jean, Manuel de droit diplomatique, Salmon, Jean, Université Libre de Bruxelles, Brulant, 1994.

31 McClanahan, Grant V., Diplomatic Immunity: Principles, Practices, Problems, C. Hurst \& Co. Publishers, 1989, pp. 84-88. Para una visión de las fuentes históricas de la Convención de Viena de 1961, se recomienda: Richard Langhorne (1992). "The Regulation of Diplomatic Practice: the Beginnings to the Vienna Convention on Diplomatic Relations", Review of International Studies, 18, 1961, pp 6-14. Resulta grato observar que, en su texto, Langhorne cita como un antecedente del derecho diplomático el Tratado que firmaron México y Gran Bretaña sobre inmunidades diplomáticas y consulares en 1826, p. 5.

32 McClanahan, op. cit. p. 95; Farhangi op. cit. p. 1520. 
Esta revista forma parte del acervo de la Biblioteca Jurídica Virtual del Instituto de Investigaciones Jurídicas de la UNAM

matices propios, pero sin obstaculizar la eficiente realización de aquellos actos realizados en ejercicio de funciones diplomáticas en el territorio de los Estados receptores. ${ }^{33}$

Ese criterio de funcionalidad impacta tanto el día a día de las representaciones diplomáticas como el de la maquinaria estatal del anfitrión; ¿hasta qué grado, en pos del respeto al trabajo diario de los diplomáticos, está justificado que las inmunidades representen un valladar infranqueable para que el Estado anfitrión aplique sobre ellos su ley? Para resolver esta cuestión desde una perspectiva técnico-jurídica están los tribunales. ${ }^{34} \mathrm{Tal}$ y como se mencionara antes, estos juegan un papel vital en el respeto al tratado y, en ese sentido, el régimen de inmunidades se emparenta con la interpretación constitucional y de reglas procesales que aquellos realizan.

$\mathrm{Al}$ respecto, nos ceñimos a un mero ejemplo como punto de análisis de nuestro estudio: el artículo 104, fracción VIII, de la Constitución mexicana. Lacónica, en su estructura actual, reza: "Los tribunales de la Federación, conocerán de los casos concernientes a miembros del Cuerpo Diplomático y Consular”.

Esta sección tan concreta del artículo 104 abre la puerta a un mosaico de interpretaciones constitucionales que, forzosamente, impactan los alcances domésticos del régimen de inmunidades de Viena. Hasta el día de hoy no existen criterios jurisprudenciales específicos que determinen, en primera instancia, si se hace referencia al cuerpo diplomático acreditado en México o bien, al Servicio Exterior Mexicano.

33 O’Neill, op. cit. p. 666. Brower, un detractor del régimen de inmunidades, inicia su discurso afirmando la regla general de funcionalidad como eje para regular la conducta de los sujetos de la Convención, de ahí -mediante claroscuros- acentúa un pretendido abuso generalizado de aquellas por parte de los diplomáticos. Con independencia de su sesgo, la descripción que hace del principio es sencilla y acertada cuando dice: "The Vienna Convention drafters relied upon the functional necessity theory. The functional necessity theory links immunities and privileges to the performance of diplomatic functions and refuses them where no such links exist. Under the theory, receiving States grant diplomats immunities and privileges to protect them from coercion by the receiving State or individuals within it. Otherwise, diplomats, subject to economic or political pressure, would be forced to rely on the receiving State's goodwill. Such reliance would hamper the diplomat's independence and ability to effectively represent the sending State". "Brower Privileged Outlaws: Diplomats, Crime and Immunity”, 20, Suffolk Transnat'l L. Rev., pp. 475, 486 y 487

34 Brown, Jonathan, "Diplomatic Immunity: State Practice Under the Vienna Convention on Diplomatic Relations”, International and Comparative Law Quarterly, 1988, p. 46. 
Esta revista forma parte del acervo de la Biblioteca Jurídica Virtual del Instituto de Investigaciones Jurídicas de la UNAM www.juridicas.unam.mx

Lo que pareciera un mero juego de palabras tiene amplias implicaciones jurídicas. De hacer referencia a diplomáticos extranjeros el presente estudio nos llevaría a determinar si esta pequeña fracción es, en realidad, el asidero constitucional para la aserción de inmunidades a ese universo de individuos. Esta es nuestra hipótesis de trabajo.

En México aún se encuentra en ciernes la concreción de una ley de inmunidades, ${ }^{35}$ por tanto el único fundamento constitucional que permite la aplicación del derecho de Viena es, en puridad, el artículo 133 como cláusula de supremacía, de incorporación y marco de referencia para toda la maquinaria estatal. Sin embargo, basados en nuestra hipótesis la citada fracción del artículo 104 podría ser un fundamento adicional por cuanto hace a un aspecto concretísimo: la aserción de inmunidades por parte de tribunales federales (como corte competente) en procesos judiciales.

Actualmente la práctica mexicana, impulsada por la Secretaría de Relaciones Exteriores, ha buscado informar a los tribunales sobre el necesario respeto a las inmunidades de Viena dada su naturaleza convencional y vinculante; con ello se ha pretendido limitar la apertura de controversias contra el cuerpo diplomático acreditado en México. Sin embargo, consideramos que el verbo "conocer" utilizado por la fracción del artículo en comento abre la posibilidad a que los tribunales nacionales le interpreten como una competencia implícita en el texto constitucional que prima facie concediera jurisdicción personal sobreponiéndose al tratado por ser un fundamento constitucional. ${ }^{36}$

35 Al carecer México de una ley sobre inmunidades diplomáticas, su regulación se lleva a cabo a través de meros instrumentos administrativos como la Guía de protocolo y las únicas disposiciones legales respecto a las inmunidades son las relativas a los delitos contra éstas en los códigos penal federal y de justicia militar. Véase Portilla Gómez, Juan Manuel, op. cit., pp. 147 y 148 .

36 Esto implicaría un entendimiento restrictivo del derecho internacional y, de cierto modo, un acercamiento al sistema dualista. Sin embargo, se considera que la factibilidad de este escenario es grande si se considera que la jerarquía de Viena dentro del sistema mexicano se da en la medida en que existe un fundamento de incorporación y la Convención ingresa (con sus detalles y figuras) al sistema; sin embargo en caso de que el articulo 104 represente un fundamento constitucional per se la Convención no solo tendría que ceñirse a la cláusula de incorporación para operar sino en un caso concreto también a la fracción VIII del artículo. Con ello, si no se delimita prudentemente el alcance de la fracción, podría limitarse la aplicación de Viena por medio de Cortes cuya interpretación sea más tendiente a la conservación del orden nacional intocado más que a la congruencia con el derecho internacional. 
La complejidad del planteamiento es grande. En ese sentido, consideramos que la interpretación y tratamiento que Estados Unidos ha dado a sus figuras constitucionales pueden servirnos para moldear un parámetro de claridad sobre aquellas que incorporadas en nuestra Constitución son oscuras aún.

Para tal fin el presente estudio se dividirá en las siguientes secciones: primeramente nos centraremos en la descripción de este fenómeno en Estados Unidos: aspectos constitucionales, práctica judicial y matices parroquiales; luego haremos lo propio con los matices mexicanos y cerraremos con un par de conclusiones y propuestas para una ley de inmunidades en México.

\section{VISIÓN ESTADOUNIDENSE}

\section{Asidero constitucional}

El contenido de la fracción VIII del artículo 104 constitucional se ha reflejado en los tres mayores documentos constitucionales de la historia independiente de México. Su influencia, desde una perspectiva constitucional comparada, es la subsección 2 de la sección 2 del artículo III de la Constitución nor teamericana: In all cases affecting Ambassadors, other public Ministers and Consul [...] the Supreme Court shall have original jurisdiction.

Este fragmento es tan especifico que per se no brinda elementos suficientes para su interpretación. Se hace necesario observar el contexto general del artículo III para vincularlo con los matices del texto constitucional mexicano.

La visión de Hamilton sobre el fortalecimiento del gobierno central ante el complejo entramado de poder poseído por los Estados, tuvo un punto culminante en la construcción del artículo III. ${ }^{37}$ El liberalismo como médula ideológica de Estados Unidos no sólo imbuye la redondez del discurso de los derechos civiles y de la economía del XVIII sino también la ratio política de las competencias de las entidades federativas entre sí y en su relación

37 Amar, Akhil Reed, "Neo-Federalist View of Article III: Separating the Two Tiers of Federal Jurisdiction, A”, Boston University Law Review, 65, 1985, pp. 209. 
Esta revista forma parte del acervo de la Biblioteca Jurídica Virtual del Instituto de Investigaciones Jurídicas de la UNAM www.juridicas.unam.mx

frente al gobierno nacional. Es decir, la de una continua tensión ${ }^{38}$ - que subsiste hasta el día de hoy — entre los intentos de la federación por influir o intervenir en los dominios estatales y la de estos últimos buscando extender sus cotos de acción disminuyendo las capacidades de la federación; en ese sentido hay una mayor proclividad al fomento del silencio, de las omisiones federales, que de sus acciones potencialmente intrusivas. ${ }^{39}$

La relevancia sistémica del artículo III es la de un perímetro que dibuja los límites de la influencia de los Estados, no únicamente en torno a la materia o jurisdicción territorial de ciertas controversias, sino esencialmente frente a la toma de decisiones del gobierno nacional; en tanto que el último respeta las áreas tradicionalmente concedidas a ellos. ${ }^{40}$ Sirvió pues, junto con la cláusula de supremacía del artículo VI, y la décima y onceava enmiendas, para plantear los términos de la relación entre las entidades políticas y territoriales del país.

Dicho de otro modo, el Poder Judicial Federal salvaguardaría el respeto a la Constitución no sólo por su naturaleza de pacto fundacional ni por su indudable protección a ciertos derechos considerados fundamentales, sino por razones de mayor pragmatismo. ${ }^{41}$ Es decir, sería el valladar impuesto a los Estados para no obstruir ni robar las funciones concedidas por ellos mismos al gobierno nacional. ${ }^{42}$ Entre ellas, hasta la fecha, se encuentra todo aquello relativo a las relaciones internacionales del vecino país. ${ }^{43}$

38 Pfander, James E., "Article ITribunals, Article III Courts, and the Judicial Power of the United States”, Harvard Law Review, 2004, pp. 643-776. Sumado a lo anterior para ahondar más en la tensión entre Estados y Federación conviene otear el fantástico volumen editado por George L. Haskins y Herbert A. Johnson donde explican con detalle el primer periodo de la Corte Suprema de los Estados Unidos, bajo la batuta de Marshall, que mediante casos como Marbury v. Madison y Martin v. Hunter Lessee, dibujó algunos alcances de las Cortes hacia otras ramas del Gobierno Federal y hacia las Cortes estatales. La visión hamiltoniana, refieren, se encontraba en franca desavenencia con la visión jeffersoniana tendente al empoderamiento de los Estados y de una Corte mucho más limitada. Haskins, George L. y Johnson, Herbert A., Foundations of Power: John Marshall, Volume II, pp. 96-102 y 324-344.

39 Freund, Paul A., "A Supreme Court in a Federation: Some Lessons from Legal History”, Columbia Law Review, 1953, pp. 600-602. Así como: Martínez, Jenny S., “Towards an International Judicial System", Stan. L. Rev.56, 2003, p. 502.

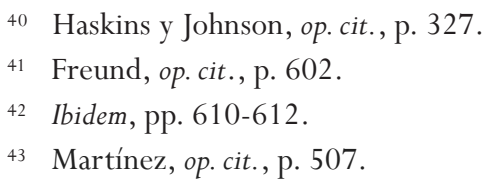


Esta revista forma parte del acervo de la Biblioteca Jurídica Virtual del Instituto de Investigaciones Jurídicas de la UNAM

Así pues, la segunda sección del artículo III tendría la misión de frenar la interpretación distorsionada de tratados y costumbre internacional por parte de los Estados evitando así un galimatías de aproximaciones al derecho internacional por medio de precedentes contradictorios. Como consecuencia de lo anterior, el artículo III fomentó la preeminencia del derecho internacional como parte integrante de la cláusula de supremacía. Con esto último, tanto las normas federales como los tratados, eventualmente comunicados gracias al aislamiento de los asuntos internacionales como competencia exclusiva de la federación, serian interpretadas de manera definitiva por el Poder Judicial Federal.

Esto desde luego impactó el día a día de los tribunales estatales pues redujo su competencia interpretativa y los obligó a observar los ruling que en la materia proveyera la Suprema Corte de Justicia en Washington. ${ }^{44}$ Incluso, en aquellos casos donde la jurisdicción fuese concurrente se verían obligados a aplicar como norma sustantiva la de carácter federal, ${ }^{45}$ en tanto que - como quedaría fijo tiempo después - procesalmente aplicarían sus propias normas. ${ }^{46}$

En este tenor, la parte del artículo III que influiría el texto mexicano sería consecuencia lógica de lo anterior: preeminencia del derecho federal (incluyendo las normas internacionales) sobre el estatal y, por ello, una limitación jurisdiccional sobre los Estados para resolver cualquier asunto internacional de manera definitiva. Bajo esta visión el texto del artículo III que nos ocupa no deja lugar a dudas: se trata del cuerpo diplomático acreditado en los Estados Unidos. A guisa de ejemplo considérense los siguientes casos.

El primero es United States v. Ravara ${ }^{47}$ resuelto en 1793, apenas iniciado el sistema judicial de los Estados Unidos. En él un Justice Iredell prudente y precursor del discurso establecido después en Marbury v. Madison sobre la relevancia del Poder Judicial Federal dice: "For obvious reasons of public

44 Haskins y Johnson, op. cit., pp. 336-341.

45 Counsel should be aware that 28 USC section 1351 provides that district courts shall have original jurisdiction of the courts of the states, of all civil actions and proceedings against members of a mission or members of their families. This statute has been held to divest state courts of subject matter jurisdiction over those cases.

46 Erie Rule.

47 United States v. Ravara, 27 F. Cas. 714, 715, 1794 U.S. App. LEXIS 26, *1, 2 Dall. 299 (C.C.D. Pa. 1794). 
Esta revista forma parte del acervo de la Biblioteca Jurídica Virtual del Instituto de Investigaciones Jurídicas de la UNAM

policy, the Constitution intended to vest an exclusive jurisdiction in the Supreme Court, upon all questions relating to the Public Agents of Foreign Nations".

De nueva cuenta obsérvese la tensión entre el gobierno federal y los estados. El espíritu detrás de esta breve cita de Ravara es el de aclarar que la preeminencia de la federación en los asuntos internacionales resultaba indisputable.

Tanto Ravara como posteriormente United States v. Ortega ${ }^{48}$ reafirman el papel preponderante del Poder Judicial ante los estados en la aplicación del derecho internacional y, más aún, en el ánimo de asirse del texto constitucional para reafirmar su preeminencia. Así, ha quedado claro para las cortes estadounidenses que esta disposición se remite exclusivamente a los enviados diplomáticos extranjeros y que, en ese sentido, debe ser la federación quien resuelva las controversias relativas a dichos agentes.

Todo ello tiene origen en la seminal decisión de Respublica v. Longchamps de $1784 .{ }^{49}$ De suma relevancia es la consideración que hace sobre las inmunidades concedidas a los enviados de naciones extranjeras. "The person of a public minister is sacred and inviolable. Whoever offers any violence to him, not only affronts the sovereign he represents but also hurts the common safety and well-being of nations".

La cita anterior hace referencia a la inmunidad del diplomático, como una especie de aura de inviolabilidad ante los interlocutores del país acreditante. Es decir, quien lo dañe e impida el ejercicio de sus funciones oficiales hace lo propio contra el soberano que representa. En esta seminal decisión la Suprema Corte sienta precedente sobre la incorporación de costumbre internacional atinente a inmunidades diplomáticas dentro del sistema jurídico americano; reafirma el papel preponderante del gobierno federal en asuntos internacionales y pone énfasis en la importancia del respeto a las inmunidades. Esto último reviste importancia pues Longschamps sienta las bases para que el Poder Judicial federal pudiera ejercer jurisdicción en controversias sobre diplomáticos como lo dispone el artículo III.

48 United States v. Ortega, 24 U.S. (11 Wheat.) 467, 468 (1826).

49 Respublica v. De Longchamps, 1 U.S. 111, 115, 1 L. Ed. 59, 61, 1784 U.S. LEXIS 116, *11-12, 1 Dall. 111 (Pa. Ct. of Oyer \& Terminer 1784). 
Esta revista forma parte del acervo de la Biblioteca Jurídica Virtual del Instituto de Investigaciones Jurídicas de la UNAM

\section{Inmunidades en Estados Unidos: algunos matices}

Los tres precedentes en cita tienen más de ciento cincuenta años de haberse creado. La conclusión preliminar ejemplificada en ellos si bien cierta es también superficial, no hay nada oculto bajo el sol. En aquel entonces la costumbre internacional era la fuente normativa principal en materia de inmunidades para todos aquellos asuntos que Washington o cualquier capital tuviera que resolver en su trato mutuo. Sí, inmunidades en general sin adjetivo que las califique.

Es decir, junto con la inmunidad diplomática que Grotius y Vattel debaten veremos que Estados Unidos ha desarrollado sendas doctrinas jurídicas sobre otras connotaciones que por momentos pueden confundirse con facilidad con la de carácter diplomático, no sólo por su nomenclatura similar sino especialmente por la multitud de capas conceptuales que poseen y que son compartidas en arenas de litigio y por tanto el case law las analiza sin diferenciarles con pulcritud. Inicialmente, está la inmunidad concedida a los estados frente a la federación y entre ellos mismos (que aquí no interesa ni siquiera mencionar), luego está la denodada doctrina de la inmunidad soberana cuya paternidad sobre dos enfoques teóricos ha planteado debates entre cortes americanas y, finalmente, la inmunidad diplomática.

A manera de nota, es propicio comentar brevemente algunos aspectos sobre la segunda connotación dado que puede confundirse fácilmente con el régimen de inmunidades diplomáticas en Estados Unidos. La inmunidad soberana se refleja en dos sentidos: a través de una doctrina desarrollada en case law denominada Act of State y a través de una norma: la Foreign Sovereignty Immunity Act.

La primera de ellas es la que provoca mayor confusión. Surge con el holding en Underhill v. Hernandez $z^{50}$ de 1897 y alcanza un momento de mayor desarrollo con Sabbatino ${ }^{51}$ en 1964 para tomar nuevos bríos, casi treinta

50 Underhill v. Hernandez, 168 U.S. 250, 252, 18 S.Ct. 83, 84, 1897.

51 Banco Nacional de Cuba v. Sabbatino, 376 U.S. 398, 400, 84 S.Ct. 923, 926 (1964). Un interesante razonamiento en Sabbatino es el siguiente: "Every sovereign state is bound to respect the independence of every other sovereign state, and the courts of one country will not sit in judgment on the acts of the government of another done within its own territory. Redress of grievances by reason of such acts must be obtained through the means open to be availed of by sovereign powers as between themselves". 
Esta revista forma parte del acervo de la Biblioteca Jurídica Virtual del Instituto de Investigaciones Jurídicas de la UNAM www.juridicas.unam.mx

años después con W. S. Kirkpatrick \& Co v. Environmental Tectonics Copr., Int'1, ,2 $^{\text {s2 }}$ Esta doctrina se relaciona tenuemente con nuestro objeto de estudio pues se origina en el concepto de igualdad soberana y considera que el derecho internacional impone límites a los Estados para ejercer su jurisdicción entre ellos.

Grosso modo en esta triada de precedentes se afirma que los actos soberanos ejecutados por agentes de un Estado extranjero gozan de una presunción de validez que las cortes domésticas deben respetar y por tanto no deben ejercer su jurisdicción para resolver controversias emanadas de aquellos. Estos actos se denominan de jure imperii. No obstante, lo anterior sufre tres excepciones: cuando intervenga el Ejecutivo como líder de las relaciones internacionales; cuando se determine que los actos son de naturaleza privada y comercial (de jure gestionis ${ }^{53}$ ) o bien cuando - con base en la cláusula de supremacía - el derecho internacional lo disponga. Esto se acerca al marco conceptual de Viena.

Sobre todo, tomemos en cuenta la dicotomía de actos de jure imperii y de jure gestionis pues intelectualmente resulta tentador vincularlas como parte de la práctica estadounidense (desarrollada por el Departamento de Estado) para marcar los parámetros en la definición de un acto realizado en el ejercicio de funciones oficiales o, dicho de otro modo, diplomáticas.

Los actos realizados por diplomáticos acreditados ante el Departamento de Estado son actos de jure imperii para la doctrina de Act of State, en tanto

52 W. S. Kirkpatrick \& Co. v. Envtl. Tectonics Corp., Int'l, 493 U.S. 400, 401, 110 S.Ct. 701, 702,1990. De acuerdo con este caso: “Act-of-state doctrine did not apply in a dispute over the allegedly illegal awarding of a Nigerian construction contract because nothing in the unsuccessful bidder's suit required the court to declare invalid the official act of a foreign sovereign".

53 Los actos de jure gestionis, de naturaleza comercial o privada; se encuentran regulados generalmente por las entidades federativas. Esta distinción en general ha tendido a fortalecer la jurisdicción estatal en la resolución de controversias ligadas con diplomáticos, un ejemplo clásico es Ohio ex rel. Popovici v. Agler, sobre el divorcio de un vicecónsul rumano en 1930; en él se establece que actos jurídicos como divorcios, compra ventas privadas o actos de carácter comercial como préstamos personales o hipotecas no se encuentran bajo el esquema federal de inmunidades; de ahí que sean las Cortes locales quienes tengan potestad para ejercer jurisdicción sobre estos casos.

con independencia de esta arista de análisis, la regla general subsiste. Resultaba importante mencionarla pues, consideramos, que muestra la forma tan propia en que Estados Unidos regula la relación de sus entidades políticas.

Ohio ex rel. Popovici v. Agler, 280 U.S. 379, 382, 50 S.Ct. 154, 154 (1930). 
Esta revista forma parte del acervo de la Biblioteca Jurídica Virtual del Instituto de Investigaciones Jurídicas de la UNAM

que para Viena son actos resguardados por el principio de funcionalidad. Guardan un cierto parentesco en su lógica. En ese sentido, tanto el acto que puede originar la controversia, como el acto de exigir a la Corte que se abstenga de ejercer su jurisdicción con base en inmunidades soberanas, podría decirse, son actos de jure imperii conforme la Convención de Viena. En este sentido, observe el dictum ${ }^{54}$ en Harris \& Co. Adver., Inc. v. Republic of Cuba de $1961^{55}$ que determina: "The claim of sovereign immunity is usually reserved to diplomatic representatives of the country involved, combined with suggestions to be obtained through the Department of State addressed to the court".

Asimismo, los actos de jure gestionis también pudieran asimilarse al marco diplomático debido a la excepción que establece el artículo 31 de la Convención, según la cual no se concede inmunidad ante las cortes por actos privados en materia comercial o civil.

Sin embargo, no debemos confundirlas. Primeramente porque la base interpretativa en ambas es diametralmente opuesta. La doctrina es una innovación de las cortes parroquial y un tanto obscura. El marco de Viena es claro y deviene de un compromiso internacional. Asimismo, la diferencia concreta que inicia su separación conceptual es que el acto postulado por la doctrina de Act of State debe surgir en el territorio de un Estado soberano de tal modo que Estados Unidos no tendría potestad para dudar de su validez o impugnarlo — por encontrarse fuera de la jurisdicción de sus cortes - ni para ejecutar medidas, generalmente económicas (incautación de bienes, congelamiento de activos o cuentas bancarias), que afecten al Estado soberano.

Esto último es más contundente si se considera que Sabbatino se da en el marco de la R evolución cubana y de la expropiación de la industria azucarera; en virtud de la cual actores privados con demérito económico

54 Según las cortes han distinguido entre obiter dicta y ratio decidendi (o holding para los americanos) al sostener que la última posee carácter vinculante en tanto la primera es meramente contingente. La primera, dice Dueñas Ruiz, "es algo que se dice de paso, carece de carácter vinculante”. Es un concepto más amplio que ratio decidenci enfocada únicamente al razonamiento que verdaderamente resolverá el caso en cuestión y sobre el cual, de ser aceptado por la Corte que resuelve, se erigirá precedente, sin embargo existen en Estados Unidos ejemplos de dicta que han configurado doctrinas de gran complejidad con una amplia progenie de casos. Véase Ruiz Dueñas, Óscar José, Lecciones de Hermenéutica Jurídica, 5a. ed., Universidad del Rosario, 2009, p. 105.

55 Harris \& Co. Adver., Inc. v. Republic of Cuba, 127 So. 2d 687, 688 (Fla. Dist. Ct. App. 1961) 
Esta revista forma parte del acervo de la Biblioteca Jurídica Virtual del Instituto de Investigaciones Jurídicas de la UNAM www.juridicas.unam.mx

en virtud de aquel acto demandaron a Cuba por daños, alegando que esa decisión eminentemente doméstica era contraria a una ley estadounidense y al derecho internacional.

La dicotomía imperii-gestionis fue recogida en 1952 en la famosa carta que el consultor jurídico del Departamento de Estado, Jack B. Tate, ${ }^{56}$ enviara al Acting Attorney General de Estados Unidos en aquel momento. Su visión restrictiva de la aserción de inmunidad soberana ha traído más divergencias (y problemas) que consensos (y soluciones) para las cortes americanas. Primeramente, no define la distinción entre un acto de jure imperii y gestionis. Asimismo, no brinda elementos a las cortes para determinar qué autoridad decidirá la cuestión anterior: si las cortes bajo una valoración técnica de pruebas o el Departamento de Estado analizando la mayor conveniencia para desarrollar política exterior. Finalmente, no determina quién deberá responder a la Corte si un agente diplomático o la capital del Estado soberano involucrado.

La práctica del Departamento de Estado continúa con sus claroscuros. La doctrina de Act of State no ha sido definida en todos sus límites hasta el día de hoy. ${ }^{57}$ Sin embargo, desde nuestra perspectiva quedaría clara su relación paternal con el ejercicio del artículo III en la medida que regula la intervención del Poder Judicial en la arena internacional por medio de litigios y, en este sentido, la confusión con Viena proviene de que en la práctica ella choca con una faceta de las funciones realizadas por diplomáticos extranjeros ante cortes federales.

56 El Departamento de Estado continuó con su política de solicitar a las Cortes el reconocimiento de inmunidades para Estados con los que se mantenía una relación amistosa hasta la creación de la Carta Tate. Con ella obró un golpe de timón y Estados Unidos paso de una teoría que respetaba totalmente la inmunidad soberana a una de carácter restrictivo, la Carta sostiene: "According to the classical or absolute theory of sovereign immunity, a sovereign cannot, without his consent, be made a respondent in the courts of another sovereign. According to the newer or restrictive theory of sovereign immunity, the immunity of the sovereign is recognized with regard to sovereign or public acts (jure imperii) of a state, but not with respect to private acts (jure gestionis)... [I]t will hereafter be the Department's policy to follow the restrictive theory... in the consideration of requests of foreign governments for a grant of sovereign immunity". Citada por Niehuss, John M., "International Law: Sovereign Immunity: The First Decade of the Tate Letter Policy”, Michigan Law Review, vol. 60, núm. 8, junio de 1962, pp. 1148.

57 Bazyler, Michael J., "Abolishing the Act of State Doctrine”, University of Pennsylvania Law Review, 1986, p. 333. 
Por su parte, la FSIA no ofrece conflictos con Viena. Su espíritu, en términos reducidos, es el de llevar a la jurisdicción de las cortes estadounidenses, nada menos que a Estados soberanos, pero no a individuos. Esto último incluso ya fue establecido por la SCOTUS en el reciente caso Samantar v. Yousuf. ${ }^{58}$ Así pues, según el holding en Von Dardel v. Unión de Repúblicas Socialistas Soviéticas $^{59}$ la SCOTUS determinó que el texto de la FSIA no contraviene norma convencional alguna en tanto que la Convención de Viena no contiene disposiciones restrictivas para la FSIA. De tal suerte corren paralelas sin generar antinomias.

Esta separación queda clara en Skeen v. Federative Republic of Brazil,${ }^{60}$ un interesante caso decidido en 1981 por la Corte Federal de Distrito para el Distrito de Columbia, en el que se determinó que un Estado soberano no podía ser llevado a Corte — con base en la FSIA — debido a un acto ilícito cometido por uno de sus nacionales con inmunidad diplomática otorgada conforme a Viena - . La Corte decidió abordar las dos cuestiones de modo separado, considerando que el reconocimiento de inmunidades conforme a Viena, como un acto soberano, no podía traducirse en una responsabilidad directa sobre la conducta ilícita que el individuo cometiera; por tanto el acto ilícito no debía ser visto como actos soberanos conforme a la FSIA.

En 1790 Estados Unidos creó su primera ley en la que adoptó la visión de Longschamps sobre la inmunidad diplomática como un absoluto. De tal suerte, este criterio de inmunidad sin resquicio de excepciones, garantizado en la ley de 1790 fue aceptado como un principio de derecho internacional que, al paso del tiempo, fue ampliamente salvaguardado con fundamento en el principio de funcionalidad. Es decir, tal y como estableciera el Chief Justice Marshall en un dictum sobre The Schooner Exchange v. $M^{\prime} F a d d o n^{61}$ de 1812, un diplomático no podría cumplir sus funciones de representante si fuera forzado a aparecer ante la Corte del estado receptor.

Ahora bien, esta visión de la funcionalidad como un concepto absoluto para justificar inmunidades diplomáticas ante las cortes recibe una amplia aceptación en Estados Unidos y no es sino con el nacimiento de la Con-

58 Samantar v.Yousuf, 560 U.S. 305, 305, 130 S.Ct. 2278, 2280 (2010).

59 Von Dardel v. Union of Soviet Socialist Republics, 623 F. Supp. 246, 248 (D.D.C. 1985).

60 Skeen v. Federative Republic of Brazil, 566 F. Supp. 1414, 1415 (D.D.C. 1983).

61 The Schooner Exch. v. McFaddon, 11 U.S. (7 Cranch) 116, 135 (1812). 
Esta revista forma parte del acervo de la Biblioteca Jurídica Virtual del Instituto de Investigaciones Jurídicas de la UNAM

vención de Viena, concentrada en una visión mucho más equilibrada de la funcionalidad, que el Congreso de los Estados Unidos decide aprobar una nueva ley, consciente de que la ley de 1790 respondía a una realidad distinta incompatible con la dinámica internacional contemporánea. En ese contexto nace la ley de 1978 que sustituye el impresionante ejemplo de longevidad legislativa de la de 1790.

La ley de 1978 es incorporada en el pantagruélico United States Code, su estructura es frugal con sólo ocho artículos, del 251 al 259; de los cuales incluso cinco están derogados actualmente. Básicamente incorpora en su estructura el esquema de la Convención de Viena por referencia, es decir, sólo indica que el Tratado regulará la materia objeto de la ley. Más importante aún es la sección 254d centrada en la aserción de inmunidad diplomática por parte del Poder Judicial Federal, se transcribe para mayor claridad:

Any action or proceeding brought against an individual who is entitled to immunity with respect to such action or proceeding under the Vienna Convention on Diplomatic Relations, under section 254bor 254c of this title, or under any other laws extending diplomatic privileges and immunities, shall be dismissed. Such immunity may be established upon motion or suggestion by or on behalf of the individual, or as otherwise permitted by law or applicable rules of procedure.

En 1978 la nueva norma recoge las mayores excepciones establecidas por elTratado con lo que el criterio de funcionalidad se ve ligeramente acotado o, si se prefiere, mejor delimitado. Sin embargo, la limitación fue mínima y sólo se refirió a la naturaleza de los actos que excluye el artículo 31 de la propia Convención. Es decir, la inmunidad se ejerce a menos que el motivo de la controversia sea por actos privados relativos a bienes inmuebles, sucesiones o créditos adjudicados al diplomático fuera de sus funciones oficiales.

Por su parte, la práctica general del gobierno del vecino país, forjada durante más de ciento cincuenta años, era la de escuchar en primera instancia el dicho del Departamento de Estado que reconocería la personalidad de un posible sujeto a la jurisdicción de las cortes como diplomático. Si esto sucedía la propia la corte desestimaba la demanda contra el diplomático por falta de jurisdicción personal (lack of personal jurisdiction).

Ese esquema general de interacción entre la Convención de Viena, incorporada al sistema estadounidense y la Diplomatic Relations Act, se ve ade- 
Esta revista forma parte del acervo de la Biblioteca Jurídica Virtual del Instituto de Investigaciones Jurídicas de la UNAM

rezado por matices brindados a partir de la interpretación de las Cortes mismas. Es ahí donde podemos tomar algunas notas interesantes para observar una muestra práctica de régimen de inmunidades diplomáticas.

Por ejemplo, la Corte Suprema en el caso U.S. v. Tapia ${ }^{62}$ de 1984 sostuvo que un diplomático no tiene standing para alegar per se una violación a la Convención de Viena cuando el Estado acreditante no haya protestado la posible violación. Esto aplicaría en un momento procesal concreto cuando el diplomático ha sido ya llevado ante la Corte y le corresponde solicitar ad cautelam el desechamiento de la demanda. Así pues, bajo un argumento que observa los derechos contenidos en el tratado como puramente soberanos, sólo el Estado tiene derecho a exigir el acatamiento de las inmunidades. Sin embargo en múltiples casos federales ${ }^{63}$ se ha determinado que para establecer inmunidad diplomática, será prueba con carácter de jure et de jure el reconocimiento que el Departamento de Estado haga en ese sentido.

Por otro lado, con independencia de lo anterior, varias cortes federales ${ }^{64}$ han establecido que el reconocimiento por parte del Departamento de Estado se centra en la calidad del individuo como representante, sin embargo

62 U.S. v. Tapia, 1984 U.S. App. LEXIS 19862, *1 (11th Cir. Aug. 3, 1984).

63 Tanto en U.S. v. Al-Hamdi, (resuelto en 2004 por la Corte Federal para el cuarto circuito con sede en Virginia), como en González Paredes v.Vila (decidido por la Corte Federal de Distrito para el Distrito de Columbia) The court in Republic of Philippines by Cent. Bank of Philippines v. Marcos, 665 F. Supp. 793 (N.D. Cal. 1987), held that whether a diplomatic agent is entitled to diplomatic immunity is a matter for the State Department to decide. The court stated that for the courts: "It is enough that the [sending state] has requested immunity, that the State Department has recognized that the person for whom it was requested is entitled to it, and that the State Department's recognition has been communicated to the court". The court added that although it had been asserted that the State Department's decisions are reviewable by the courts, "the courts have generally accepted as conclusive the views of the State Department as to the fact of diplomatic status". The court in Abdulaziz v. Metropolitan Dade County, 741 F.2d 1328, 40 Fed. R. Serv. 2d 110 (11th Cir. 1984), held that once the United States Department of State has regularly certified a visitor to the United States as having diplomatic status, courts are bound to accept that determination. The court in Slater v. Biehl, 793 A.2d 1268 (D.C. 2002), observed that the courts generally accept as conclusive the views of the State Department as to the fact of diplomatic status. The court in Matter of Terrence K., 135 A.D.2d 857, 522 N.Y.S.2d 949 (2d Dep't 1987), stated that it is well established that a certificate issued by the United States Department of State attesting to the diplomatic status of an individual or individuals is conclusive and will not be reviewed by the courts.

64 Tabion v. Mufti, 73 F.3d 535, 3 Wage \& Hour Cas. 2d (BNA) 65, 131 Lab. Cas. (CCH) P 33344 (4th Cir. 1996), Diallo v. State, 994 A.2d 820 (Md. 2010) asi como U.S. v. Noriega, 746 
Esta revista forma parte del acervo de la Biblioteca Jurídica Virtual del Instituto de Investigaciones Jurídicas de la UNAM

cuando esto no se da resta el análisis sobre el acto como tal, para determinar si se acoge al principio de funcionalidad y por tanto si es un acto fuera de la jurisdicción de la Corte. Para resolver esta cuestión las cortes deberán acogerse a un hybrid standard que mezcle consideraciones jurídicas (interpretación de textos) y factuales (valoración de pruebas).

En Traore v. State ${ }^{65}$ de 1981, se determinó que la ley de 1978 no podría ser interpretada para operar de forma retroactiva. La Corte sostuvo que si bien la ley no expresaba de forma clara el modo de su aplicación, por otro lado la falta de un ánimo legislativo claro para hacerla retroactiva obligaba a interpretar su aplicación como únicamente prospectiva. Esta posición se contrapone a la expresada en Knab v. Republic of Georgia, ${ }^{66}$ de 1998, que desarrolla la tesis de la inmunidad diplomática residual según la cual los actos realizados con base en el principio de funcionalidad conservan en el tiempo un aura de inmunidad. Esto significa que con base en una ficción jurídica, si una Corte quiere ejercer jurisdicción "hoy" sobre un individuo en virtud de un acto realizado “ayer”, en ejercicio de alguna función diplomática, la Corte no podría hacerlo pues durante la realización del acto el individuo era inmune.

De lo anterior podemos inferir que si bien la DRA y el derecho internacional son las bases normativas para interpretar y aplicar el régimen de inmunidades diplomáticas en aquel país, han sido las cortes y el Departamento de Estado quienes han realizado lo que pudiéramos denominar "notas al margen" de las ocho secciones de la DRA, ya sea ampliando o reduciendo el espectro del principio de funcionalidad con barroquismos estadounidenses, determinando aspectos de la aplicación del tratado y más importante aún, mediante resquicios procesales; han brindado a su marco institucional una preeminencia de facto sobre el marco jurídico brindado por Viena.

Con independencia de esto que responde a una comprensión nacional del rol que juega el derecho internacional en su sistema, consideramos que la existencia de un marco jurídico sobre inmunidades tiene una raíz hondísima en el sistema jurídico estadounidense que corre desde el artículo III de su Constitución hasta Viena, pasando por el artículo VI y la Diplomatic

F. Supp. 1506 (S.D. Fla. 1990), aff'd on other grounds, 117 F.3d 1206, 47 Fed. R. Evid. Serv. 786 (11th Cir. 1997),

65 Traore v. State, 290 Md. 585, 586, 431 A.2d 96, 97 (1981)

66 Knab v. Republic of Georgia, 1998 U.S. Dist. LEXIS 8820, *1, 1998 WL 34067108 (D.D.C. May 29, 1998) 
Relations Act y que brinda pues, al sistema, un rasgo tendente a la garantía del Estado de derecho.

Resulta indudable que un asidero constitucional con la fuerza histórica poseída por los artículos III y VI brinda a los diplomáticos un espacio único de interacción con Estados Unidos cuyo éxito o fracaso se mide observando la reducción o mayor apertura de un nicho de diálogo en el que las inmunidades juegan un papel vital. Es decir, si la relación bilateral goza de la fluidez necesaria quizá las cortes no tengan que intervenir con la fuerza potencial contenida por el artículo III.

\section{VISIÓN MEXICANA}

\section{Asidero constitucional}

El artículo III de la Constitución americana y su espíritu hamiltoniano no tuvieron un parangón en la construcción del sistema de gobierno en México, o no al menos del mismo modo. En el Pacto de 1791 las trece colonias se unen para formar un Estado soberano y ceden a la federación ciertas competencias con lo que queda latente (hasta la fecha) un ánimo de desconfianza y temor de invasión competencial entre los estados y la capital. En México fue la capital la que cedió a los estados algunas competencias, el contexto fue distinto. ${ }^{67}$

A pesar de lo anterior, el citado artículo se replicó: en la Constitución de 1824 (en los artículos 137 y 138); en la Constitución de 1857 (en los artículos 97 y 100) y en la Constitución de 1917 en el artículo que motiva este ejercicio.

Únicamente el artículo 137 de la Constitución de 1824 señala que la Corte Suprema de Justicia conocerá: "De los negocios civiles y criminales de los enviados diplomáticos y cónsules de la república”. El calificativo final haría pensar que, si bien se seguía el modelo de definir la competencia del Poder Judicial federal desde el texto constitucional; en términos materia-

67 Para una comprensión integral del tema se recomienda: Vázquez, Josefina Zoraida (ed.), El establecimiento del federalismo en México, 1821-1827, México, El Colegio de México, 2003. Asimismo, Barragán Barragán, José, Introducción al federalismo (la formación de los poderes 1824), Colección, 1978. 
Esta revista forma parte del acervo de la Biblioteca Jurídica Virtual del Instituto de Investigaciones Jurídicas de la UNAM

les la disposición regularía controversias del Servicio Exterior Mexicano, no del cuerpo diplomático acreditado en México.

Sin embargo, el calificativo "de la República” muere con la Constitución de 1857 y en ella se reitera el modelo estadounidense, heredándolo además a la de 1917. Es decir, sólo se dice: "agentes diplomáticos y cónsules". Incluso, cabe señalar que los términos usados por la fracción VIII del artículo 104 constitucional son más ambiguos que los anteriores; generalmente por agente diplomático se hace referencia a diplomáticos extranjeros, sin embargo en el artículo actual se dice: miembros del cuerpo diplomático y consular.

Esta ambigüedad se zanja tenuemente, no de forma definitiva ni vinculante, mediante una tesis aislada de 1920. La Corte que construye este criterio sólo se centra en dirimir la competencia de dos tribunales estatales sobre una controversia que podría involucrar una jurisdicción concurrente (estado-federación) y en la que por salud constitucional sería más adecuado el foro federal.

Es de recalcarse que, siguiendo el espíritu de fortalecimiento al Poder Judicial Federal emanado de la Constitución americana, y quizá retomando el espíritu del artículo 137 de 1824 la Corte explica:

DiPlomáticos y CÓNSULES. Conforme a la fracción VI del artículo 104 de la Constitución, corresponde a los tribunales federales conocer de los casos concernientes a los miembros del cuerpo diplomático y consular; y desde el momento en que esa disposición no distingue entre los miembros del cuerpo diplomático y consular mexicanos, en el extranjero y los de los gobiernos extranjeros en el país, debe considerarse que tal disposición legal se refiere tanto a unos como a otros; y aun cuando los actos que dichos individuos hayan ejecutado, lo sean con el carácter de particulares, deben conocer de ellos las autoridades federales, porque, dado su carácter diplomático o consular, pueden afectar las relaciones internacionales.

Este criterio no es el que prima. Actualmente, el criterio jurisprudencial establece que el artículo 104 regula al cuerpo diplomático acreditado en México. Ciertamente sólo hace referencia a controversias laborales; sin embargo bien valdría la pena pensar que esto podría extenderse a materias de carácter público.

COMPETENCIA. DiplomáticOS. LAS JUNTAS FEDERALES DE CONCILIACIÓN Y ARBITRAJE LA TIENEN PARA CONOCER DE LOS JUICIOS LABORALES SEGUIDOS EN CONTRA 
DE LOS. De la armónica interpretación de los artículos 41, 73, fracción XX, 76, fracción I, 89, fracción X, 123, Apartado “A”, fracción XX y 133 de la Constitución de los Estados Unidos Mexicanos, en relación con el diverso numeral 104, fracción VI, de la propia Carta Magna, aplicado este último por analogía, se deduce que corresponde a las Juntas Federales de Conciliación y Arbitraje conocer de los juicios laborales seguidos en contra de miembros del cuerpo diplomático y consular, aun cuando la fracción XXXI, apartado A, del invocado artículo 123, no incluya expresamente dicha hipótesis, y aun cuando la demanda relativa se dirija en lo particular a las personas que forman parte de tales órganos y no en contra del gobierno que representan, ya que el precepto 104 invocado no distingue en cuanto a que la competencia de las autoridades federales sea únicamente cuando los diplomáticos o miembros del cuerpo consular actúen en nombre de la nación que los ha acreditado, sino que categóricamente dispone que dicha competencia se surte "en los casos concernientes a miembros del cuerpo diplomático y consular”, por lo que como la ley no distingue no se debe distinguir, concluyéndose que la acción ejercitada es de carácter federal, atendiendo a la investidura de los demandados.

En tales términos, todo apunta a que el espíritu del artículo III es el que imbuye al artículo 104, fracción VIII. Si bien es verdad que en México el sistema federal opera de forma distinta a Estados Unidos; ambos sistemas comparten un mismo objetivo: la regulación de las relaciones internacionales por medio de una sola ventanilla: el gobierno federal.

\section{Matices mexicanos}

Con base en lo anterior pudiéramos adelantar una conclusión sustancial para nuestro estudio: la fracción VIII habla de diplomáticos extranjeros. Hasta aquí todo es claro y vemos una coincidencia entre los dos países, nuestra hipótesis de trabajo se ha demostrado preliminarmente. Como dijimos en un principio, junto con la delimitación de las competencias otorgadas a los poderes judiciales en ambos países, también destaca como rasgo común la inclusión de una cláusula de supremacía.

Prima facie apuntamos que el sistema estadounidense con su intrincado modelo de incorporación era diferente al mexicano. El segundo, con una incorporación directa de Viena haría pensar que tenemos la mitad del tra- 
Esta revista forma parte del acervo de la Biblioteca Jurídica Virtual del Instituto de Investigaciones Jurídicas de la UNAM

bajo resuelto pues entonces la propia Convención actuaría como norma doméstica para resolver controversias que requieran el análisis de inmunidades. Sin embargo, consideramos que esto no es así de simple.

Entre los tribunales de México y Estados Unidos no sólo prima la sustantiva diferencia entre el precedente como fuente normativa protagónica en el segundo que en México no encuentra parangón con la jurisprudencia entendida como una fuente secundaria. En Estados Unidos, como ya vimos, el case law ha concretado una serie de criterios vigentes sobre el peso específico y la interacción de Viena y sus inmunidades con el sistema jurídico-político de aquel país. Si bien este rasgo tan propio y pundonoroso de los estadounidenses, no tiene símil en México; por nuestra parte hemos construido un refinado derecho procesal constitucional, desarrollado desde mediados del XIX, sin posible comparación con las limitadas competencias y recursos disponibles en el sistema americano.

Es precisamente esta exquisitez jurídica con lo que en México sopesamos el alcance de las normas internacionales en el foro interno. No, desde luego, con la flexibilidad que posee el case law pero sí con la definitividad requerida para regular — desde la cúspide de la jerarquía judicial hasta las bases - la conducta de las cortes sobre el entendimiento de la Constitución. Esto, como veremos, impacta la concreción del régimen de inmunidades en nuestro país.

Con base en lo anterior, será válido preguntar en qué se relaciona el juicio de amparo con las inmunidades de Viena. Pues bien, en principio brinda un derecho de acción contra actos de autoridad en demérito de los derechos humanos protegidos por la Constitución mexicana. El foro adecuado es el provisto por los juzgados y tribunales federales. Entre esta nómina de derechos humanos se encuentran tanto los descritos en la arquitectura constitucional como los incorporados por medio de tratados. De tal suerte, el juicio de amparo puede utilizarse como un derecho de acción genérico para cualquier derecho humano vulnerado por autoridades nacionales.

En este sentido, como se mencionara en un inicio, con la reforma constitucional de 2011, la jerarquía de los tratados en México experimentó una especie de subdivisión jerárquica entre aquellos tratados que regulan derechos humanos y los que aparentemente no lo hacen. ${ }^{68}$ Los primeros

68 Fix-Zamudio, Héctor, "El derecho internacional de los derechos humanos en las Constituciones latinoamericanas y en la Corte Interamericana de Derechos Humanos”, Revista 
Esta revista forma parte del acervo de la Biblioteca Jurídica Virtual del Instituto de Investigaciones Jurídicas de la UNAM

tendrían nivel constitucional y las antinomias que surgieran, incluso con la Constitución, se sortearon a partir de un nuevo modelo de interpretación, conforme al principio pro homine, desarrollado en el contexto regional por la Corte Interamericana en una serie de polémicos casos desde 2005.

$\mathrm{Su}$ finalidad es "acudir a la norma más protectora y/o a preferir la interpretación de mayor alcance de ésta al reconocer/garantizar el ejercicio de un derecho fundamental; o bien, en sentido complementario, aplicar la norma y/o interpretación más restringida al establecer limitaciones/restricciones al ejercicio de los derechos humanos". De tal suerte, aún aquellos tratados que vulneraran derechos humanos contenidos en otros tratados o bien en la Constitución misma podrían resultar inconstitucionales a partir de la resolución del amparo.

Ahora bien, esta explicación se relaciona con el régimen de inmunidades provisto por Viena del siguiente modo: actos realizados por diplomáticos extranjeros pueden ser llevados ante los tribunales en un juicio ordinario en materia civil, laboral o administrativa. Si el juez a cargo del caso considera que el acto anterior se encuentra bajo el amparo del esquema de funcionalidad establecido por Viena, con certeza desechará la demanda. Esto puede ser combatido por medio del amparo y en esa medida el régimen de Viena (ponderado por el primer tribunal) sería puesto a prueba judicialmente.

La relevancia de este matiz mexicano ya fue mostrada en el Amparo en Revisión 197/201 resuelto por la Segunda Sala de la Suprema Corte de Justicia de la Nación en 2013, suscitado por una controversia laboral promovida contra el Instituto Latinoamericano de la Comunicación Educativa (ILCE), organismo multilateral con una sede en la Ciudad de México. Concretamente, la demandante solicitó el ejercicio de medidas cautelares contra ILCE, a lo que se negó la Junta Especial Número Dieciséis de Conciliación y Arbitraje. Ese acto fue combatido por medio del Amparo.

Lacónica en la síntesis que realiza de los conceptos de violación, la SCJN estima que:

El artículo 1o. constitucional garantiza a todas las personas la titularidad de todos

los derechos constitucionales. Al ser los derechos de los trabajadores derechos

Latinoamericana de Derecho, núm. 1, 2004, pp. 148-150, y Castilla, Karlos, "El control de convencionalidad: un nuevo debate en México a partir de la sentencia del caso Radilla Pacheco”, Anuario Mexicano de Derecho Internacional, vol. XI, 2011, pp. 593-624. 
Esta revista forma parte del acervo de la Biblioteca Jurídica Virtual del Instituto de Investigaciones Jurídicas de la UNAM

humanos, ${ }^{69}$ el artículo 22, punto 3, de la Convención de Viena sobre Relaciones Diplomáticas resulta inconstitucional, en virtud de que impide a la quejosa hacer valer esos derechos frente a entes que tienen inmunidad diplomática.

El artículo 22 dispone el principio de inviolabilidad de los locales de la misión y al respecto la SCJN razonó que el espíritu de dicho artículo violaba los derechos laborales del artículo 123 constitucional y las leyes emanadas del mismo. Específicamente el artículo 22.3 otorga inmunidad a las representaciones diplomáticas en relación con sus bienes, e impide que sean registrados, embargados o sujetos a algún medio de ejecución. En este sentido, otorga mayores beneficios al patrón que a los trabajadores, y rompe con el equilibrio que debe haber entre éstos conforme al artículo 2o. de la Ley Federal del Trabajo, pues impide el secuestro de los bienes del organismo internacional al que tienen derecho los trabajadores.

Bajo esta lógica la SCJN tuvo un razonamiento de doble rasero. En primera instancia, consideró que la controversia laboral llevada ante la Junta Especial fue provocada por un acto fuera del marco de funcionalidad del artículo 31 de Viena por considerarlo un acto privado; por tanto para la Corte la inmunidad era inaceptable desde el origen mismo de la controversia. Por otro lado, suma a lo anterior una alegada inconstitucionalidad del principio de inviolabilidad dispuesto por el artículo 22.3 de Viena por constituir una limitación a los derechos laborales de la demandante del secuestro de bienes. La Corte usa dos raseros pero con un solo efecto: limitar las inmunidades diplomáticas concedidas al organismo.

Así, en una jurisprudencia reciente, la Segunda Sala dispuso:

INMUNIDAD JURISDICCIONAL. EL INSTITUTO LATINOAMERICANO DE LA COMUNICACIÓN EDUCATIVA NO GOZA DE ESA PRERROGATIVA CUANDO CONTRATA TRABAJADORES PARA CUMPLIR SUS FINES. Los Estados extranjeros o los organismos internacionales cuando actúan en un Estado ajeno como cualquier particular, realizan actos que, por regla general, no están protegidos por el beneficio o la prerrogativa

69 En un fallo en materia laboral de la Suprema Corte de Argentina contra la embajada rusa en Buenos Aires, conocido como Manauta, señaló la existencia de "un derecho humano" a la jurisdicción protegido por el derecho internacional y que al no tratarse de un acto de jure imperii no aplicaba el criterio de inmunidad absoluta. Véase Fernández Madrid, Horacio, "Juicios contra estados extranjeros. Teoría restringida de la inmunidad de jurisdicción”, Revista Jurídica de la Universidad de Palermo, año 1, núm. 1, abril de 1996, pp. 150 y 151. 
Esta revista forma parte del acervo de la Biblioteca Jurídica Virtual del Instituto de Investigaciones Jurídicas de la UNAM

de la inmunidad jurisdiccional. Conforme a lo anterior, el acto jurídico a través del cual el referido Instituto realiza la contratación de personal no queda comprendido dentro de aquellas actividades inherentes a su objeto o funciones, ya que sólo es una actividad accidental que debe realizar para el cumplimiento de sus objetivos, acto jurídico que debe ser calificado como realizado por particulares, esto es, el organismo internacional cuando como persona moral de derecho privado que celebra un contrato para que le presten un trabajo personal subordinado, despliega una actividad de contratación comprendida en lo que la doctrina denomina actos de gestión.

Si se observa el discurso contenido por la novel jurisprudencia, puede traer a la memoria una reminiscencia de la dicotomía imperii-gestionis propuesta por la doctrina de Act of State y, por ello, una ligera incardinación entre las inmunidades soberana y diplomática que hemos explicado con anterioridad. En otras palabras, la SCJN con este criterio pareciera retomar una visión restrictiva de las inmunidades diplomáticas que, en este caso, fue aplicada contra un organismo internacional. Las consecuencias de una sentencia así contra un gobierno extranjero en virtud de los actos realizados por sus diplomáticos indudablemente representarían un hito, no sólo interno sino en las relaciones exteriores de México.

Quizá más impresionante nos resulte el papel jugado por el amparo en este ejercicio de interpretación. La vinculación de las inmunidades diplomáticas y los derechos laborales queda establecida en términos poco equilibrados. A pesar del criterio que citamos apenas según el cual las Juntas de Conciliación no ejercerán su jurisdicción sobre diplomáticos, en el extremo contrario, la Segunda Sala de la SCJN ha dispuesto que esto es inviable cuando se violen derechos humanos.

Nadie combate la validez irrestricta de los derechos humanos. Sin embargo, se hace necesario abordar con mayor esmero el rol de las inmunidades en el amparo pues la Suprema Corte de Justicia de la Nación en general, frente a controversias entabladas por particulares, interpretará la Constitución conforme al marco que éste provee, de tal suerte la interpretación conforme no permitirá, aunque parezca paradójico, un análisis más esmerado del derecho internacional en México. De tal suerte, el sesgo es ineludible y hasta cierto punto obliga a un sencillo cálculo aritmético que restará al marco de Viena. La Convención de Viena, bajo la lógica del artículo 1o., apunta a encontrarse en una posición poco fortalecida frente a un juicio de amparo. 
Esta revista forma parte del acervo de la Biblioteca Jurídica Virtual del Instituto de Investigaciones Jurídicas de la UNAM

\section{CONCLUSIONES}

En vista de todo lo expuesto consideramos que la visión compartida de este tema constitucional aderezado con el contenido de Viena, nos ha brindado suficiente claridad como para observar cuán relevante es, para la materialización del derecho internacional en sede interna, la práctica judicial.

La médula común del artículo III y de la cláusula de supremacía han brindado a los dos países un piso común para articular un régimen de inmunidades. El protagonismo del case law en Estados Unidos permitió el desarrollo de teorías útiles para determinar algunos parámetros de aplicación en esta materia. Con independencia de lo relativos que pueden llegar a ser consideramos que su riqueza discursiva ha impactado en México. En ese país han sido las Cortes quienes han desarrollado una verdadera ley de inmunidades con reglas, excepciones, matices y ámbitos de aplicación que ni siquiera en la Convención, mucho menos en la propia Diplomatic Relations Act, están descritos.

Frente a un panorama de práctica estatal como ese, consideramos que la mejor salida para brindar certeza al régimen de inmunidades en México es mediante una norma jurídica que subsane las lagunas y que brinde una interpretación clara a la interacción que entre los artículos 133 y 104, fracción VIII, existe alrededor de Viena. La falta de la contundencia gozada por el case law como fuente normativa en México debe encontrar un símil en un proyecto de ley de inmunidades.

Antes de brindar un par de propuestas sobre el contenido de dicha norma exponemos algunas conclusiones luego del ejercicio analítico que realizamos.

En primer lugar, confirmamos que los numerales analizados, para ambos países, hablan sobre el cuerpo diplomático acreditado en ellos. Esto como se demostró involucra el primer punto de contacto entre una facultad constitucional concedida a los tribunales para acertar jurisdicción y la aplicación de inmunidades con base en Viena. Esto requiere claridad por medio de un desarrollo legislativo posterior que delimite bien el alcance de ambas y evite un oscuro problema difícil de resolver.

En este sentido, Estados Unidos y su serie de inmunidades ha permeado en la aplicación de las de tipo diplomático en sus foros. Concretamente la mezcla conceptual y práctica (en casos concretos) entre inmunidad sobera- 
na y diplomática ha impulsado una poco clara distinción entre la doctrina de Act of State y las inmunidades de Viena. Esto último es, como observamos, un modo de entender el derecho internacional propio de los Estados Unidos que, no necesariamente, es el mejor para un país como México.

Ciertamente la dicotomía imperii-gestionis utilizada en la práctica internacional para comprender la diferencia entre un acto conforme al criterio de funcionalidad y otro dentro de las excepciones del artículo 31 de Viena es relevante. Esto no puede entenderse como una asimilación total de la doctrina de Act of State en una vertiente diplomática. La oscuridad de aquella sólo incrementaría la resolución de un problema para acertar jurisdicción tomando en cuenta que con independencia del carácter imperii o gestionis los tribunales estadounidenses sólo han tomado el parámetro del artículo 5o. de Viena (que describe las funciones diplomáticas enunciativamente) con un mero sentido descriptivo. Así, la definición unilateral de qué sí y qué no responde a un acto de jure imperii sería un ejercicio que consideramos exagerado y fuera del ámbito de interpretación de Viena para las cortes mexicanas.

Adicionalmente, el rol del amparo como se mostró podría provocar un entendimiento poco prístino del complejo régimen de inmunidades provisto por Viena. Su naturaleza y amplitud de derecho de acción podría provocar la interpretación de Viena como un tratado de segundo nivel por debajo de aquellos que analizan derechos humanos. Si bien lo deseable es que la interpretación más proclive a la protección del individuo sea la que prevalezca, en la práctica lo que se observa es una subdivisión de tratados que en un escenario de litigio podrían tener una presunción de inconstitucionalidad. En ese sentido, si bien las inmunidades potencialmente evitan la acción de las cortes, esto último no es discrecional sino sólo justificable en la medida en que el alto a su jurisdicción sea para permitir el ejercicio de funciones diplomáticas.

De ahí que sea necesario proponer una serie de pasos para guiar la interpretación de los tribunales (y de las propias representaciones diplomáticas) al determinar el alcance de las inmunidades que correspondan al caso. Asimismo, previo al inicio de un litigio, tomando en cuenta la algidez de las inmunidades como un medio jurídico para forzar o evitar contiendas a nivel político, sería útil revisar el papel de la mediación como una opción viable.

Por ello, consideramos que la fracción VIII del artículo 104 podría ser el fundamento constitucional para una ley reglamentaria que regulara el 
Esta revista forma parte del acervo de la Biblioteca Jurídica Virtual del Instituto de Investigaciones Jurídicas de la UNAM

ejercicio de jurisdicción ante tribunales federales en casos que involucren diplomáticos extranjeros. De tal suerte adoptando el modelo de Viena, podría adicionarse una necesaria definición de inmunidad soberana para explicar nítidamente su relación con los actos bajo el esquema de funcionalidad pero separándola de forma clara para enfocarse en la inmunidad concedida al oficial al que se le conceden conforme a Viena.

Del mismo modo, deberá darse un rol concreto a la jurisprudencia existente (y futura) como una fuente doméstica que impactara la aplicación de la Convención. Asimismo, deberán determinarse los derechos que gozan los diplomáticos involucrados en un litigio de materias concretas tomando Viena como el parámetro de minimis para tal fin. En este sentido, sería necesario definir qué rol tendría el juicio de amparo en la aserción de inmunidades. No para disminuir sus efectos positivos en la protección de derechos humanos sino para clarificar el alcance de un tratado con la importancia de Viena frente a la fórmula del artículo 1o. y los tratados de derechos humanos.

\section{BIBLIOGRAFÍA}

\section{Libros y artículos}

Abu Warda, Nahib, "Las migraciones internacionales", Revista de Ciencias de las Religiones, Anexo XXI, 2007.

ACEVEDo, Domingo, "Relación entre el derecho internacional y el derecho interno", Revista del Instituto Interamericano de Derechos Humanos, núm. 2, vol. 16, julio-diciembre de 1992.

AmAR, Akhil Reed, "Neo-Federalist View of Article III: Separating the Two Tiers of Federal Jurisdiction”, Boston University Law Review, 1985.

Arenal Fenochio, Jaime del, Un modo de ser libres: independencia y constitución en México (1816-1822), El Colegio de Michoacán, 2002.

Ayala Corao, Carlos, "La Jerarquía constitucional de los tratados relativos a derechos humanos y sus consecuencias”, en MÉndeZ SILVA, Ricardo (coord.), Derecho internacional de los derechos humanos. Memoria del VII Congreso Iberoamericano de Derechos Constitucional, México, Instituto de Investigaciones Jurídicas, UNAM, 2002. 
Esta revista forma parte del acervo de la Biblioteca Jurídica Virtual del Instituto de Investigaciones Jurídicas de la UNAM

Barragán Barragán, José, Introducción al federalismo (la formación de los poderes 1824), 1978.

BAZYLER, Michael J., "Abolishing the Act of State Doctrine", University of Pennsylvania Law Review, 1986.

BeCERra Ramírez, Manuel, “Tratados internacionales se ubican jerárquicamente por encima de las leyes y en un segundo plano respecto de la Constitución Federal (Amparo en revisión 1475/98)", Cuestiones Constitucionales. Revista Mexicana de Derecho Constitucional, México, núm. 3, julio-diciembre de 2000.

, La recepción del derecho internacional en el derecho interno, México, UNAM, Instituto de Investigaciones Jurídicas, 2012.

BRAVO LiRA, Bernardino, "El derecho indiano después de la independencia de América Española. Legislación y doctrina jurídica”, Historia, núm.19, Santiago, 1984.

Brower, Charles H., "International Immunities: Some Dissident Views on the Role of Municipal Courts”, Va.J. Int'l L. 2000.

BROWN, Jonathan, "Diplomatic immunity: State practice under the Vienna convention on diplomatic relations", International and Comparative Law Quarterly, 1988.

Buergenthal, Thomas, Public International Law in a nutshell, West Publishing Company, 2002.

CARbonell, Miguel, "Las fronteras y los derechos fundamentales", Obra en homenaje a Rodolfo Cruz Miramontes, México, UNAM, 2008, t. II.

Castilla, Karlos, "El control de convencionalidad: un nuevo debate en México a partir de la sentencia del caso Radilla Pacheco", Anuario Mexicano de Derecho Internacional, vol. XI, 2011.

, "El principio pro persona en la administración de justicia", Cuestiones Constitucionales, 2009.

Corwin, Edward S., "The Higher Law Background of American Constitutional Law”, Harvard Law Review, 1929.

DAHL, Robert Alan, How Democratic is the American Constitution?, Yale University Press, 2003.

DenZA, Eileen, Diplomatic Law, Commentary on The Vienna Convention on Diplomatic Relations. Oxford University Press, 2008.

DiCKInSOn, Edwin D. "The Law of Nations as Part of the National Law of the United States", University of Pennsylvania Law Review, 1952. 
Esta revista forma parte del acervo de la Biblioteca Jurídica Virtual del Instituto de Investigaciones Jurídicas de la UNAM

DueÑas Ruiz, Óscar José, Lecciones de Hermenéutica Jurídica, 5a. ed., Universidad del Rosario, 2009.

EISSA-BARroso, Francisco A., "Mirando hacia Filadelfia desde Anáhuac: La Constitución estadounidense en el Congreso Constituyente mexicano de 1823-1824", Política y Gobierno, núm. 17, 2010.

FarhangI, Leslie Shirin, "Insuring Against Abuse of Diplomatic Immunity”, Stanford Law Review, 1986.

FERNÁNDEZ MADRID, Horacio, “Juicios contra estados extranjeros. Teoría restringida de la inmunidad de Jurisdicción”, Fallo Manauta, Revista Jurídica de la Universidad de Palermo, año 1, núm. 1, abril de 1996.

Ferrajoli, Luigi, "Libertad e inmigración”, Revista Internacional de Filosofía Política, núm. 22, 2003, en http://dialnet.unirioja.es/servlet/articu lo? codigo=930442 (consultada el 3 de junio de 2015).

FiX-ZAMUDIO, Héctor, "El derecho internacional de los derechos humanos en las Constitucio nes latinoamericanas y en la Corte Interamericana de Derechos Humanos”, Revista Latinoamericana de Derecho, núm. 1, 2004.

Freund, Paul A., "A Supreme Court in a Federation: Some Lessons from Legal History”, Columbia Law Review, 1953.

Haskins, George L. y Johnson, Herbert A., Foundations of Power:John Marshall, 1801-1815, vol. 106, núm. II, 1983.

IWASAWA, Yuji, "The Doctrine of Self-Executing Treaties in the United States: A Critical Analysis”, 26 Va.J. Int'l L., 1986.

Jordan J., Paust, "Self-Executing Treaties", The American Journal of International Law, vol. 82, núm. 4, octubre de 1988.

KnOWlton, Robert J., The Early Influence of the United States Constitution in the Western Hemisphere: The Cases of the Mexican Constitution of 1824 and Bolivar's Ideas, University of Wisconsin-Milwaukee, Center for Latin America, 1988.

LANGHORNE, Richard, "The regulation of diplomatic practice: the beginnings to the Vienna Convention on Diplomatic Relations, 1961", Review of International Studies, 1992.

MarTíneZ, Jenny S., “Towards an International Judicial System”, Stan. L. Rev. 56, 2003.

Mcclanahan, Grant V., Diplomatic Immunity: Principles, Practices, Problems, C. Hurst \& Co. Publishers, 1989. 
Esta revista forma parte del acervo de la Biblioteca Jurídica Virtual del Instituto de Investigaciones Jurídicas de la UNAM

Merryman, John Henry y PÉrez-Perdomo, Rogelio, The Civil Law Tradition: an Introduction to the Legal Systems of Europe and Latin America, Stanford University Press, 2007.

Merryman, John Henry, "On the Convergence (and Divergence) of the Civil Law and the Common Law”, Stan. J. Int'l L., 1981.

NIEHUSS, John M., International Law: Sovereign Immunity: The First Decade of the Tate Letter Policy Michigan Law Review, vol. 60, núm. 8, junio de 1962.

North American Center for Transbounder Studies, Reconociendo el valor real del comercio bilateral con México, Estados Unidos, Arizona State University, 2010.

O’neILl, Terry A., “A New Regime of Diplomatic Immunity: The Diplomatic Relations Act of 1978”, Tulane Law Review, 1980.

PfAnder, James E., “Article ITribunals, Article III Courts, and the Judicial Power of the United States”, Harvard Law Review, 2004.

Portilla GómEZ, Juan Manuel, "El Estado mexicano como sujeto de derecho diplomático", Revista Mexicana de Política Exterior, núm. 79-80, junio de 2007.

Rabasa, Emilio O., Historia de las Constituciones mexicanas, México, UNAM, Instituto de Investigaciones Jurídicas, 2000.

RAMSEY, Michael D., The Constitution's Text in Foreign Affairs, Harvard University Press, 2007.

SAlmon, Jean, Manuel de droit diplomatique, Brulant, Université Libre de Bruxelles, 1994.

Serrano, Fernando, Historia mínima de las Constituciones en México, 2013.

SiLVA GARCía, Fernando, "Derechos humanos y restricciones constitucionales: Reforma constitucional del futuro vs. Interpretación constitucional del pasado (Comentario a la C.T. 293/2011 del Pleno de la SCJN)”, Cuestiones Constitucionales. Revista Mexicana de Derecho Constitucional, núm. 30, enero-junio de 2014.

SMITH, Watson, "Influences from the United States on the Mexican Constitution of 1824", Arizona and theWest, 1962.

STARKE, Joseph Gabriel, "Monism and Dualism in the Theory of International Law”, British Year Book of International Law, 1936.

STRAusS, David A., "Common Law Constitutional Interpretation", The University of Chicago Law Review, 1996.

Tena Ramírez, Felipe, "Constituciones", Leyes fundamentales de México, 1808-1982, México, Porrúa, 1982. 
Esta revista forma parte del acervo de la Biblioteca Jurídica Virtual del Instituto de Investigaciones Jurídicas de la UNAM

Tiersma, Peter, “The Textualization of Precedent", Notre Dame Law Review, 2007.

VÁzQuEZ, Carlos Manuel, "The Four Doctrines of Self Executing Treaties”, 89 A.J.I.L, 695-696.

VÁZQUEZ, Josefina Zoraida (ed.), El establecimiento del federalismo en México, 1821-1827, El Colegio de México, 2003.

Velasco, Juan Carlos, "Dejando atrás las fronteras. Las Políticas migratorias ante las exigencias de la Justicia Global”, ARBOR Ciencia, Pensamiento y Cultura, España, julio-agosto de 2010.

ZAPATA-BARRERO, Ricard, "La retórica de la ciudadanía y la inmigración”, Revista Claves de la Razón Práctica, núm. 177, noviembre de 2007.

\section{Jurisprudencia estadounidense}

Banco Nacional de Cuba v. Sabbatino, 376 U.S. 398, 400, 84 S.Ct. 923, 926 (1964).

González Paredes v. Vila, decidido por la Corte Federal de Distrito para el Distrito de Columbia.

Harris \& Co. Adver., Inc. v. Republic of Cuba, 127 So. 2d 687, 688 (Fla. Dist. Ct. App. 1961)

Knab v. Republic of Georgia, 1998 U.S. Dist. LEXIS 8820, *1, 1998 WL 34067108 (D.D.C. May 29, 1998)

Ohio ex rel. Popovici v. Agler, 280 U.S. 379, 382, 50 S.Ct. 154, 154 (1930). Respublica v. De Longchamps, 1 U.S. 111, 115, 1 L. Ed. 59, 61, 1784 U.S.

LEXIS 116, *11-12, 1 Dall. 111 (Pa. Ct. of Oyer \& Terminer 1784)

Samantar v.Yousuf, 560 U.S. 305, 305, 130 S.Ct. 2278, 2280 (2010).

Skeen v. Federative Republic of Brazil, 566 F. Supp. 1414, 1415 (D.D.C. 1983). Tabion v. Mufti, 73 F.3d 535, 3 Wage \& Hour Cas. 2d (BNA) 65, 131 Lab.

Cas. (CCH) P 33344 (4th Cir. 1996), Diallo v. State, 994 A.2d 820 (Md. 2010)

The Court in Republic of Philippines by Cent. Bank of Philippines v. Marcos, 665 F.

Supp. 793. N.D. Cal. 1987.

The Paquete Habana, 175 U.S. 677, 678, 20 S.Ct. 290, 291 (1900).

The Schooner Exch. v. McFaddon, 11 U.S. (7 Cranch) 116, 135 (1812)

Traore v. State, 290 Md. 585, 586, 431 A.2d 96, 97 (1981) 
U.S. v. Al-Hamdi. Resuelto en 2004 por la Corte Federal para el cuarto circuito con sede en Virginia.

U.S. v. Noriega, 746 F. Supp. 1506 (S.D. Fla. 1990), aff'd on other grounds, 117 F.3d 1206, 47 Fed. R. Evid. Serv. 786 (11th Cir. 1997),

U.S. v. Tapia, 1984 U.S. App. LEXIS 19862, *1 (11th Cir. Aug. 3, 1984).

Underhill v. Hernandez, 168 U.S. 250, 252, 18 S.Ct. 83, 84 (1897)

United States v. Ortega, 24 U.S. (11 Wheat.) 467, 468 (1826)

United States v. Ravara, 27 F. Cas. 714, 715, 1794 U.S. App. LEXIS 26, *1, 2 Dall. 299 (C.C.D. Pa. 1794)

Von Dardel v. Union of Soviet Socialist Republics, 623 F. Supp. 246, 248 (D.D.C. 1985).

W. S. Kirkpatrick \& Co. v. Envtl. Tectonics Corp., Int'l, 493 U.S. 400, 401, 110 S.Ct. 701, 702 (1990).

\section{Jurisprudencia mexicana}

Contradicción de Tesis 293/2011 "SCJN determina que las normas sobre derechos humanos contenidas en Tratados Internacionales tienen rango constitucional" Consultar: http://www2.scjn.gob. $m x /$ asuntosrelevantes / pagina / seguimientoasuntosrelevantespub.aspx?id=129659\&seguimiento $i d=556$ (consultada el 25 de julio de 2015).

Tesis de pleno LXXVI/99, TRATADOS INTERNACIONALES SE UBICAN JERÁRQUICAMENTE POR ENCIMA DE LAS LEYES FEDERALES Y EN UN SEGUNDO PLANO RESPECTO DE LA CONSTITUCIÓN FEDERAL, aprobada en la sesión privada del 28 de octubre de 1999.

Tratados internacionales y Leyes Del CONGRESO DE LA Unión EMANADAS DE La CONSTitución Federal. Su Rango CONSTitucional eS DE IGUAL JERARQUÍA SÉPTIMA ÉPOCA. TERCER TRIBUNAL COLEGIADO EN MATERIA ADMINISTRATIVA DEL PRIMER CIRCUITO, Semanario Judicial de la Federación, t. 151-156, Sexta Parte.

TRATADOS INTERNACIONALES. EL ARTÍ́CULO 133 CONSTITUCIONAL, ULTIMA PARTE, NO ESTABLECE SU OBSERVANCIA PREFERENTE SOBRE LAS LEYES DEL CONGReso de LA Unión emanadas de la CONSTITUCiÓn Federal. Gaceta del Semanario Judicial de la Federación, t. 60, diciembre de 1992, tesis P. C/92. 
Esta revista forma parte del acervo de la Biblioteca Jurídica Virtual del Instituto de Investigaciones Jurídicas de la UNAM

\section{Fuentes de Internet}

Morris, William G., "Constitutional Solutions to the Problem of Diplomatic Crime and Immunity”, Hofstra Law Review, vol. 36, iIss. 2, article 19. 2007. Available at: http://scholarlycommons.law.hofstra.edu/hlr/vol36/iss $2 / 19$.

SKOCZEK, María, "Globalización y migraciones a caballo de los siglos XX y XXI”, Actas Latinoamericanas deVarsovia, t. 27 integración versus globalización, efectos sociales, económicos y especiales, Universidad de Warsawa, Instituto de Países en Desarrollo, 2004, http://www.wgsr.uw.edu.pl/pub/uploads / actas04/04-skoczek.pdf. 